\title{
Meaning in life, psychological hardiness and death anxiety: individuals with or without generalized anxiety disorder (GAD)
}

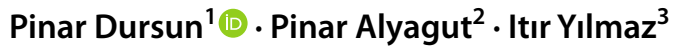

Accepted: 30 December 2021 / Published online: 8 January 2022

(c) The Author(s), under exclusive licence to Springer Science+Business Media, LLC, part of Springer Nature 2022

\begin{abstract}
Generalized anxiety disorder (GAD) is a widespread psychiatric disorder. According to the transdiagnostic approach, death anxiety can underpin predominantly somatic manifestations of GAD. Personal resilience factors such as a sense of a meaningful life, and psychological hardiness, which can protect people from developing clinical symptoms, may be lower in individuals with GAD. So far, there has been no study examining the role of meaning in life dimensions, death anxiety, and hardiness in individuals with GAD in Turkey. Thus, we aimed to investigate to what extent the GAD sample differs from the non-anxious control group in terms of death anxiety, meaning in life dimensions, and hardiness. Secondly, we examined how conceptually predicted death anxiety by meaning in life dimensions and hardiness regardless of diagnosis, age, and gender. Just before the spread of the Covid-19 pandemic, we could only recruit 38 individuals with GAD and 31 non-anxious control subjects. The Death Anxiety Scale, The Meaning in Life Questionnaire and the Psychological Hardiness Scale were administered to all the participants. The one-way MANOVA results with Bonferroni adjustment revealed that individuals with GAD significantly differed from the control group in every way. Hierarchical regression analysis displayed that the presence of meaning made the most significant contribution in predicting death anxiety. In conclusion, existential issues such as death anxiety, hardiness, and meaningful life can be emphasized for the treatment of GAD, and the presence of meaning is the most crucial antidote to avoid death anxiety in all individuals.
\end{abstract}

Keywords Generalized Anxiety Disorder · Death Anxiety · Meaning in Life · Psychological Hardiness

Generalized anxiety disorder (GAD) is a highly prevalent psychiatric disorder leading to enormous healthcare costs from $3.1 \%$ to $5.7 \%$ over a patient's lifetime (Kessler \& Wang, 2008). GAD markedly compromises an individual's quality of life and psychosocial functioning; nevertheless, most of the time, the somatic presentations are misunderstood and under-treated in primary care (Bandelow et al., 2017; Mendlowicz \& Stein, 2000). Even though the age of onset for anxiety disorders is typically in childhood or adolescence, GAD can still be expected in old age (50 years or more). The course is often chronic-recurrent (Bandelow et al., 2017)

Pinar Dursun

pdursun@aku.edu.tr; dursun.pinar@gmail.com

1 Department of Psychology, Afyon Kocatepe University, Afyonkarahisar, Turkey

2 Department of Philosophy, Afyon Kocatepe University, Afyonkarahisar, Turkey

3 Antalya Manavgat State Hospital Department of Psychiatry, Antalya, Turkey and associated with severe physical health conditions such as coronary heart disease (Martens et al., 2010; Roest et al., 2012). GAD is characterized by extreme and uncontrollable anxiety, worry, restlessness, and fatigue (American Psychiatric Association, 2013). The most common worry themes are death, illness, social rejection, isolation, and failure (Beck, 1974). Individuals with GAD report high general health concerns and physical symptoms such as cardiovascular, respiratory, neurological, gastrointestinal, or autonomic responses (Stein \& Sareen, 2015; Wittchen \& Hoyer, 2001). Furthermore, these individuals tend to misinterpret emotional and bodily reactions with catastrophic cognitions that exacerbate anxiety and worry attacks (Clark, 1986). Accordingly, Asian clinical presentations of anxiety disorders including GAD were found to be highly associated with weakness-related somatic symptoms resulted from catastrophic cognitions such as cardiac arrest, brain depletion, dangerous weakening, weak kidney, weak nerves, semen loss, limb blockage, sore neck, vomiting, dizziness, loss of mental power, headaches, or orthostatic dizziness (Hinton et al., 2009) which 
might remind us of the feelings of ontological vulnerability, worthlessness, or helplessness stemming from death awareness in our taken-for-granted lives.

Recently, the transdiagnostic approach has proposed that some dispositions, traits, or constructs such as a high level of rumination, perfectionism, avoidance, low positive affect, lack of control, and death anxiety can act as vulnerability factors in developing or maintaining various mental disorders, including anxiety disorders (Iverach et al., 2014; Menzies et al., 2019). Death anxiety as a transdiagnostic construct can likely indicate unresolved psychological and physical distress in many disorders. In support of this premise, death anxiety correlated with the symptom severity of 12 disorders (Menzies et al., 2019), distress, and the number of lifetime prognoses (Menzies \& Dar-Nimrod, 2017). Accordingly, a great deal of research indicates that death anxiety has been linked to various psychopathologies, including panic disorders (Furer et al., 1997; Starcevic, 2007), separation anxiety (Chait, 1998), eating disorders (Le Marne \& Harris, 2016; Stein et al., 2013), depression, anxiety, stress (Eshbaugh \& Henninger, 2013; Menzies et al., 2019), depression (Arndt et al., 2005), specific phobias, compulsive behaviors, social anxiety and avoidance (Strachan et al., 2007), somatization, health anxiety disorders or hypochondriasis (Noyes et al., 2002; Stolorow, 1979), obsessive-compulsive disorder (Menzies \& Dar-Nimrod, 2017; Menzies et al., 2020), and posttraumatic stress disorder (Chatard et al., 2012; Cheung et al., 2005).

\section{Death Anxiety}

In an anthropological and philosophical sense, the fundamental challenge of a human being is to face existential anxiety derived from painful knowledge of mortality or the "threat of non-being" (Fortner et al., 1999; Tillich, 1952; Yalom, 2008). This "gift" can facilitate the appreciation of life, as in Seneca's quotes (...) "all the days we have lived up to now are already in the hands of death.", or this "burden" leads people to live life in the Epicurean way through avoiding pain and death. Freud (1925) claimed that death anxiety was the first manifestation of neurosis, but later, he (1936) prioritized castration anxiety. However, he agreed that both concepts are associated with the feeling of "a sense of loss." Accordingly, a great deal of research indicated that death anxiety, fear of separation, ad loss of meaning and control, and feelings of insecurity were all found to be highly correlated (Caras, 1995; Maxfield et al., 2014; Menzies \& Menzies, 2020; Noyes et al., 2002). To an extent, death anxiety is acceptable, and many resilient individuals cope even when they face death reminders in their daily lives. However, it may not be easy to adapt to stressful conditions for some people, especially in times of high stress. These individuals can display a maladaptive way of coping with the stressors or regulating their feelings, thus developing psychopathological symptoms. Thus, in this study, one of our aims was to explore the levels of death anxiety and resilient scores in individuals with GAD by comparing with non-anxious control group in the Turkish population since there has been no study on this, to the best of our knowledge.

In dealing with death anxiety, as a leading theory in psychology, terror management theory (TMT; Greenberg et al., $1986,1990)$ suggests that people in every culture tend to use their cultural worldviews as a buffer due to avoiding death reminders or death-related thoughts. Thus, in a way, cultural standards, traditions, or beliefs transform into symbolic structures that provide some comfort and feelings of security. Nevertheless, recent studies about TMT showed that this theory has emphasized cultural defense mechanisms and the death-denying function of the cultural worldviews while ignoring personal resilience factors, except for selfesteem, which reduces anxiety derived from the effect of mortality reminders (Pyszczynski et al., 2004). There are stress-buffer personality traits or resilience factors that have been shown to provide positive adaptation in the face of difficulty, anxiety, trauma, and threats (Bonanno, 2004; Dolcos et al., 2016; Herrman et al., 2011) and to reduce or attenuate the impact of mortality inductions, especially in cultural defenses (Greenberg et al., 1993; Iverach et al., 2014).

\section{Meaning in Life}

A sense of a meaningful life plays a vital role in providing and protecting mental health. Meaning in life is defined as people's understanding of their own lives (consistent understanding of oneself, the world, and harmony) and having a purpose of pursuing in life (having an overarching set of goals or missions one is trying to achieve) (Steger et al., 2006). Even though there are debates on whether meaning in life can be constructed or discovered from life itself (see a review by Dursun \& Alyagut, 2020), the sources of meaning can vary significantly across individuals, periods, and cultures (Baumeister, 1991). Nowadays, conceptually, it is distinguished into two interrelated but distinct dimensions; the presence of meaning (experiencing the meaning) and the search for meaning (seeking more meaning in life). Recent empirical studies have shown that the presence of meaning, which is regarded as a trait-like and relatively stable resource (Steger \& Kashdan, 2007), was an indicator for promoting and maintaining physical health, based on neuroendocrine, immunological, and cardiovascular markers (Bower et al., 1998; Krause, 2004; O’Connor \& Vallerand, 1998; Smith \& Zautra, 2004), as well as mental health in terms of greater happiness and life satisfaction, less depression, distress, anxiety, and loneliness (Ishida \& Okada, 2006; Shiah et al., 2015; Steger \& Frazier, 2005; Steger \& Kashdan, 2007), and 
reductions in substance abuse (Nicholson et al., 1994) and smoking (Steger et al., 2009a, b). On the other hand, search for meaning correlates with ill-being indicators (Schulenberg et al., 2011; Steger \& Park, 2012; Steger et al., 2008a, b). So far, there has been no study that examined the role of the presence or search for meaning in a sample of GAD subjects, but we expect that presence of meaning will be lower in the GAD sample than in the non-anxious control group.

The meanings we attribute to death can have important implications for our well-being, determining our sense of meaning in life (Wong \& Tomer, 2011). Death attitudes influence how people live; for instance, people are more likely to construct meanings on extreme materialistic or hedonistic habits consciously or unconsciously due to avoiding the pain of death awareness. Similarly, Heidegger (1953) argued that the unconscious existential anxiety (angst) arising from the reality of death defines how the being (dasein) is and to what extent it "falls into life," starts to live in a mode of "being-in-the-world" and gradually transforms into "everybody" and "worldliness." When death comes to the door, this inevitable reality begins to individuate the being (dasein). The being realizes its loneliness and starts listen to itself for the first time while "everyone" becomes silent. If it succeeds in individuating, it finally begins to transform into its "authentic potential." Thus, in a way, the person's response to the reality of death determines whether s/he will reach his/her authentic self, eudaimonic life. Furthermore, Tillich (1952) indicated that a lack of meaning and emptiness evokes existential anxiety or threat of "non-being." To create a meaningful life requires an act of courage. In support, Frankl (1985) suggested that life is naturally full of meaning. Every person must discover the hidden meaning designed for him/her, but after facing and accepting mortality (see Dursun \& Alyağut, 2020, for a review). Thus, meaning-making can be an antidote for the pain of immortality.

In a similar vein, many empirical studies have demonstrated that a meaningful life is negatively correlated with death anxiety. For instance, Tang et al. (2002) found that a meaningful life is positively associated with death acceptance, decreasing death anxiety scores in Chinese university students. Similarly, Routledge and Juhl (2010) revealed that death reminders selectively increased death anxiety in individuals with lower meaning in life, whereas individuals with higher meaning did not report aggravated death anxiety. The findings of Zhang et al. (2019) displayed that the subdimensions of meaning in life, i.e. presence of meaning and search for meaning, were negatively correlated with death anxiety in Chinese older adults. On the other hand, Lyke (2013) revealed that only the search for meaning in life was significantly associated with fear of death in a community sample of participants in the USA. Interestingly, in a study conducted with a community sample in Turkey, neither the presence of meaning or search for meaning was found to be significantly associated with death anxiety (Yüksel et al., 2017). In short, so far, there have been limited and inconsistent findings regarding the relationship between the dimensions of meaning in life and death anxiety. This study also explored the relationship between meaningful life and death anxiety in a Turkish population.

\section{Psychological Hardiness}

Psychological hardiness is defined as a personality trait, set of attitudes, or a style consisting of three interrelated features (commitment, control, and challenge) that enable individuals to cope better with stress (Kobasa et al., 1982; Maddi, 1997, 1999). These dimensions are commitment (vs. alienation), which refers to feeling deeply engaged in the activities of life; control (vs. powerlessness), which refers to a desire to have an impact on consequences, decisions, circumstances, and people; and challenge (vs. security), in which potentially stressful situations are viewed as exciting and encouraging personal growth, rather than as threat (Maddi, 2004). People with hardiness skills have different perspectives of themselves and the world, which positively affects their cognitive appraisals, motivation, attitudes, and behaviors towards life's adversities (Maddi, 2002, 2004). According to Maddi (2004), choosing the future entails ontological or death anxiety. The more significant the change in a person's beliefs or routines with a future decision, the greater one feels threatened and anxious. Once death anxiety increases, one fails to overcome the past and repeatedly ruminates on habitual patterns and routines. Thus, this ritual pattern eventually leads to meaninglessness and boredom. Every decision made to embrace the future is full of anxiety, but implementing that decision leads to new knowledge and a feeling of learning, whether one fails or not (Maddi, 2004). Thus, we expect a negative correlation between death anxiety and hardiness, although very few studies have so far. In support of this assumption, Pourakbari et al. (2014) found that hardiness was associated with decreased death anxiety and increased quality of life in a sample of nurses in Iran. Similar, hardiness and death anxiety derived from the Covid-19 pandemic were inversely correlated in a sample of diabetic patients in Iran (Ezazi Bojnourdi et al., 2020). Various studies have shown that greater hardiness is associated with lower levels of somatic symptoms and anxiety (Kovács \& Borcsa, 2017; Sandvik et al., 2015; Singley et al., 2012) and neuroticism, rumination, worry, as well as with high levels of mindfulness, coping, and health (Kowalski \& Schermer, 2019). In the Turkish literature, there has been no study related to anxiety disorders and hardiness similar to other variables.

Taken together, there has been a growing interest in the role of transdiagnostic constructs, including death anxiety, that increases the vulnerability factors for the onset, course, 
or maintenance of psychopathology such as anxiety disorders (see Iverach et al., 2014; Maxfield et al., 2014). On the other hand, everyone reacts differently to adverse events. Resilience traits or attitudes such as a sense of a meaningful life and psychological hardiness enable people to better cope with the adversities and protect people developing psychopathologies such as GAD. Thus, we first aimed to explore to what extent the GAD sample differs in terms of death anxiety, meaning in life dimensions, and psychological hardiness compared to the non-anxious control group. Specifically, building a meaningful life and acquiring hardiness skills can provide many benefits or a buffer from implicit or explicit impacts of death anxiety in participants with GAD. Nevertheless, since we had an insufficient sample size to perform any moderation or mediation model analyses between resilience factors and death anxiety (Hayes, 2017), the present study aimed to explore to what extent GAD and nonanxious control subjects differ from each other in terms of death anxiety, meaning in life dimensions, and psychological hardiness. Secondly, we attempted to determine out the contributory roles of resilience factors in predicting death anxiety while controlling for the presence of diagnosis, age, and gender. Hence, this study will be the first study to include all these variables in the Turkish literature.

\section{Method}

\section{Participants and Procedure}

Recruitment for the present study occurred from June 2019 to March 2020, just before the Covid-19 pandemic. We stopped collecting data because we believed that the data structure would be different before and after the pandemic experience. Thus, the sample only consisted of 74 participants. After data screening, five outlier cases were deleted, and 38 treatment-seeking individuals with GAD (without major depression disorder as a diagnosis) and 31 non-anxious control participants remained in the data set. These 69 individuals comprised the samples on which the statistical analyses were based. Participants with GAD were recruited from outpatient psychiatric clinics of one of the state hospitals in Turkey. The individuals with GAD were selected from among the individuals who applied to the clinic for the first time, so none were using medication during data collection. Exclusion criteria were in the study as follows: a) presence of any comorbidity, b) the presence of any psychotic disorder, c) presence of dementia or another neurocognitive condition, d) acute suicidality, and (e) serious substance abuse f) using any psychotropic medications. One of the authors in the current study (M.D., adult psychiatrist) determined diagnoses using the Structured Clinical Interview for DSM-V diagnostic criteria. The mean age of participants in the GAD group was $33.23(S D=8.42)$, and $65.8 \%$ were female.

Individuals in the non-anxious control group were recruited through an announcement in the same hospital and neighborhood, and they were matched to the GAD sample concerning age and gender. After being screened with the Turkish versions of the Beck Depression Inventory and State-Trait Anxiety Scale-Trait (STAI-II) version, potential control participants were included. We also statistically compared the BDI and STAI-II scores between the non-anxious control and individuals with GAD to determine the severity of trait anxiety and the presence of clinical depression. The mean age of the non-anxious control group was 33.45 $(S D=8.77)$, and $64.5 \%$ were female. The institutional review board of the state university approved all methods and procedures, and all participants were provided informed consent.

Regarding socio-demographic variables, in the GAD sample, most participants were both elementary school graduates $(34.2 \%)$, and $31.6 \%$ higher than high school graduates (23.7\% high school), married (73.7\%), housewives (47.4\%), and living in a small town (73.7\%), and their family income mainly was minimum wage $(55.3 \%)$. Most of the participants in the non-anxious control group were middle school graduates $(51.6 \%)$, single $(58.1 \%)$, working as civil servants (41.9\%), and living in a small town (83.9\%) earning minimum wage (35.5\%). The socio-demographic variables for all participants are presented in Table 1 .

\section{Measures}

Socio-demographic Form: This form included socio-demographic questions such as age, gender, education, occupational status, marital status, psychiatric information.

Beck Depression Inventory (BDI): BDI is a 21-item self-report inventory ranging from 0 (never) to 3 (always) developed by Beck, Ward, Mendelson, Mock, \& Erbaugh in 1961 and revised in 1979 (Beck et al., 1979) to measure the clinical symptoms of depression, namely, the presence and severity of emotional, motivational, cognitive and somatic components. The scores range from 0 to 84 , and greater scores indicate greater depression severity. BDI scores are commonly classified as "no depression" (1-11), low mood disturbance" (12-16), "moderate depression" (17-30), and "high depression" (31-84). The split-half reliability coefficient was reported to be 0.74 . Teğin first translated the BDI into Turkish in 1980 and it was later revised by Hisli (1989), who calculated the Cronbach's alpha coefficient as 0.74. In this study, Cronbach's alpha coefficient was calculated to be 0.85 . 
Table 1 Socio-demographic characteristics of the samples

\begin{tabular}{|c|c|c|c|c|}
\hline & \multicolumn{2}{|c|}{$\begin{array}{l}\text { Generalized Anxiety } \\
\text { Disorder }(\mathrm{N}=38)\end{array}$} & \multicolumn{2}{|c|}{$\begin{array}{l}\text { Non-anxious } \\
\text { Control } \\
(\mathrm{N}=31)\end{array}$} \\
\hline & $\mathrm{N}$ & $\%$ & $\bar{N}$ & $\%$ \\
\hline \multicolumn{5}{|l|}{ Gender } \\
\hline Female & 25 & 65.8 & 20 & 64.5 \\
\hline Male & 13 & 34.2 & 11 & 35.5 \\
\hline \multicolumn{5}{|l|}{ Educational Status } \\
\hline Literate & 3 & 7.9 & 2 & 6.5 \\
\hline Elementary & 13 & 34.2 & 12 & 38.7 \\
\hline Middle School & 10 & 26.3 & 16 & 51.6 \\
\hline High School & 9 & 23.7 & 1 & 3.2 \\
\hline University & 3 & 7.9 & 2 & 6.5 \\
\hline \multicolumn{5}{|l|}{ Marital Status } \\
\hline Single & 9 & 23.7 & 18 & 58.1 \\
\hline Married & 28 & 73.7 & 11 & 35.5 \\
\hline Divorced & 0 & 0 & 1 & 3.2 \\
\hline Widowed & 1 & 2.9 & 1 & 3.2 \\
\hline \multicolumn{5}{|l|}{ Occupational Status } \\
\hline Student & 5 & 13.2 & 5 & 16.1 \\
\hline Housewife & 18 & 47.4 & 11 & 35.5 \\
\hline Civil servant & 10 & 26.3 & 13 & 41.9 \\
\hline Employee/worker & 4 & 10.5 & 2 & 6.5 \\
\hline Employer & 0 & 0 & 0 & 0 \\
\hline \multicolumn{5}{|l|}{ Family Income } \\
\hline Minimum wage & 21 & 55.3 & 11 & 35.5 \\
\hline Moderate wage & 17 & 44.7 & 10 & 32.3 \\
\hline More than moderate & 0 & 0 & 10 & 32.3 \\
\hline \multicolumn{5}{|l|}{ Residence } \\
\hline City & 5 & 13.2 & 4 & 12.9 \\
\hline Small Town & 28 & 73.7 & 26 & 83.9 \\
\hline Rural/Village & 5 & 13.2 & 1 & 3.2 \\
\hline
\end{tabular}

State-Trait Anxiety Inventory (STAI): STAI is a 40-item selfreport scale designed by Spielberger in 1983 in order to measure the severity of state (situational- how a person feels at that moment) and trait (continual- how a person feels in general independently from any specific situation or time) anxiety. In this study, only the Trait version was used. Items were ranging from 1 (almost never) to 3 (almost always). The range of possible scores varies from a minimum score of 20 to a maximum of 80 on both the STAI-T and STAI-S subscales. STAI scores are commonly classified as "no or low anxiety" (20-37), "moderate anxiety" (38-44), and "high anxiety" (45-80). The Cronbach's alpha coefficients varied from 0.86 to 0.92 (Spielberger, 1983). The Turkish adaptation was performed by Öner and Le Comte (1985). The internal consistency of trait anxiety inventory ranged from 0.83 to 0.87 . In this study, Cronbach's alpha coefficient was calculated to be 0.97 .
Death Anxiety Scale (DAS): DAS is a 15-item self-report scale with true/false format ranging from 0 (false) to 1 (true) developed by Templer in 1970. High scores refer to the higher levels of death anxiety. The reliability coefficient determined by Kuder Richardson-20 was reported to be 0.76 (Templer, 1970). Şenol (1989) calculated psychometric properties and found the test-retest reliability as 0.86 . In this study, the Cronbach's alpha coefficient was found to be 0.91 .

The Meaning in Life Questionnaire (MLQ): MLQ is a 10 -item self-report questionnaire ranging from 1 (absolutely untrue) to 7 (absolutely true) developed to measure to what extent individuals have a meaningful life (MLQ-Presence; the degree to what extent people think and feel their lives are meaningful) and search for meaning (MLQ-S; the degree to which people search for more meaning) (Steger et al., 2006). Each dimension has five items that indicate that scores range from 5 to 35. The Cronbach's alpha coefficients were reported as 0.86 for MLQ-P and 0.87 for MLQ-S. Dursun (2012) performed a Turkish adaptation study, in which the Cronbach's alpha coefficients were reported as 0.83 for MLQ-P and 0.87 for MLQ-S. In this study, Cronbach's alpha coefficient was calculated to be 0.81 for MLQ-P and 0.88 for MLQ-S.

Psychological Hardiness Scale (Personal Views Survey $I I I-R)$ : This is an 18-item self-report scale ranging from 0 (not at all true) to 3 (entirely accurate) by Maddi and Khoshaba (2001), who revised the PVS (Maddi, 1997). The scale has three dimensions, namely commitment, control, and challenge. Higher scores indicate higher levels of hardiness. The Cronbach's alpha for total scores was calculated to be 0.88 . The Turkish adaption was conducted by Durak (2002), and the Cronbach alpha coefficient was reported to be 0.63 for total scores. The factor structure was found to be different from the original study (Durak, 2002). Thus, we used total scores of hardiness in the current study as suggested by the author, and we calculated the Cronbach's alpha coefficient as 0.85 .

\section{Statistical Analyses}

Descriptive statistics were calculated for all continuous and categorical variables. For group differences, multivariate analysis of variance (one-way MANOVA) and for the predictive role for death anxiety, one hierarchical multiple regression, and examining the associations of the variables, Pearson product-moment analysis was performed. Before running any analyses, all the scores were investigated for assumptions including normality, univariate and multivariate outliers, and multicollinearity; all were found to be satisfactory (Tabachnick \& Fidell, 2007). All statistical analyses were performed using the Statistical Package for Social Sciences (version 22.0 for Windows). 


\section{Results}

\section{General Worry Themes of the Participants}

Based on the clinical interview, the main complaints and concerns of the individuals with GAD were as follows: muscle pains, headaches, stomach pains, sleep difficulties, dry mouth, swallowing difficulties, restlessness, irritability, hypervigilance, dizziness, sometimes energy loss, difficulty concentrating, trembling, sweating, constant worry about everything, and feeling like on edge. Especially in cases of increased anxiety, they experience heartbeat (tachycardia) all day long, fear of heart attack, and compulsive checking on loved ones over the phone (reassurance seeking). For instance, one participant said that she occasionally starts late on household chores due to the need to check on every member of the family. Worry can be unbearable if their phones are turned off or relatives are somehow inaccessible. The worry themes are generally associated with catastrophic scenarios about family well-being, health issues, possible losses, accidents, or misfortunes befalling loved ones. The worry content sometimes results from economic difficulties such as bank depths, unpaid bills, house chores problems, school expenses and forensic issues, and interpersonal relations, primarily mother-inlaw conflicts and extended family matters.

\section{Comparison by Diagnosis}

As preliminary analyses, we examined the severity of trait anxiety and the presence of depression; the two samples were tested by comparisons of means with independent sample t-tests. Based on each independent sample t-test analysis, individuals with GAD diagnoses scored significantly higher on STAI-trait anxiety scores $(t(67)=-29.951$, $p<0.001)$ with higher mean scores [66.42, $(S D=6.53)$ ] than control individuals [27.19, $(S D=3.57)]$. Similarly, there were significant differences between the two groups on the BDI, indicating that individuals with GAD had significantly higher scores $(X=11.18, \mathrm{SD}=3.60)$ than non-anxious control individuals $[(X=3.25, S D=1.76, t$ $(67)=-11.192, p<0.001)]$. According to the cut-off scores of both scales, while individuals with GAD exhibited high trait anxiety severity, they had low or no depressive mood. Since our scope did not include the severity of depression or anxiety with other variables, we did not run any further analysis.

Due to investigating whether death anxiety, meaning in life dimensions, and hardiness scores differed between the two groups (GAD and non-anxious control group), a
Table 2 Summary of MANOVA analysis with GAD and non-anxious control group

\begin{tabular}{|c|c|c|c|c|c|}
\hline \multirow[b]{2}{*}{ Measures } & \multicolumn{2}{|c|}{$\begin{array}{l}\text { GAD } \\
(\mathrm{N}=38)\end{array}$} & \multicolumn{2}{|c|}{$\begin{array}{l}\text { Controls } \\
(\mathrm{N}=31)\end{array}$} & \multirow[t]{2}{*}{ ANOVA $F(1,67)$} \\
\hline & $M$ & $S D$ & $M$ & $S D$ & \\
\hline Death Anxiety & 11.60 & 2.79 & 3.23 & 2.25 & 182.330 \\
\hline Presence & 24.28 & 8.01 & 28.45 & 4.01 & 6.930 \\
\hline Search & 20.94 & 8.56 & 13.13 & 6.45 & 17.650 \\
\hline $\begin{array}{l}\text { Psychological Hardi- } \\
\text { ness }\end{array}$ & 17.71 & 3.87 & 36.54 & 4.00 & 391.245 \\
\hline
\end{tabular}

Note: Boferroni correction $(\alpha=.05 / 4$, tests $=.0125)$

Note 2: GAD: Generalized Anxiety Disorder

Table 3 Correlation Matrix and descriptive data of the variables

\begin{tabular}{lllll}
\hline Measures & 1 & 2 & 3 & 4 \\
\hline 1.Death Anxiety & 1 & $-.42^{* *}$ & $.49^{* *}$ & $-.73^{* *}$ \\
2. Presence of meaning & & 1 & $-.48^{* *}$ & $.32^{* *}$ \\
3. Search for meaning & & & 1 & $-.44^{* *}$ \\
4. Psychological Hardiness & & & & 1 \\
M & 7.84 & 26.16 & 17.44 & 26.18 \\
SD & 4.91 & 6.82 & 8.58 & 10.21 \\
$\mathrm{~N}$ & 69 & 69 & 69 & 69 \\
\hline
\end{tabular}

${ }^{* *}$ Correlation is significant at the .01 level (two-tailed)

one-way multivariate analysis of variance (MANOVA) was performed. Results indicated a significant effect of diagnosis on four dependent variables; Wilks' $\lambda[F(4,64)=116.691$, $p<0.001$, partial $\left.\eta^{2}=0.88\right]$. Univariate analyses using Bonferroni correction $(\alpha=0.05 / 4$, tests $=0.0125)$ revealed that a significant effect of diagnosis for the death anxiety $\left[F(1,67)=182.330, p<0.001\right.$, partial $\left.\eta^{2}=0.73\right]$, presence of meaning $\left[F(1,67)=6.930, p<0.01\right.$, partial $\left.\eta^{2}=0.10\right]$, search for meaning $[F(1,67)=17.650, p<0.001$, partial $\left.\eta^{2}=0.21\right]$, and hardiness $[F(1,67)=391.245, p<0.001$, partial $\left.\eta^{2}=0.85\right]$. Since there were only two groups, we did not run a posthoc analysis. As shown in Table 2, the findings revealed that the GAD and non-anxious control groups significantly differed from each other in terms of all variables, suggesting that individuals with GAD had greater death anxiety and search for meaning and the lower presence of meaning and psychological hardiness.

\section{Zero-order Correlations and Hierarchical Regression Analysis with Death Anxiety}

As depicted in Table 3, Pearson product-moment correlations were computed among death anxiety, meaning in life dimensions (presence and search for meaning), and 
psychological hardiness in all participants. Death anxiety was significantly correlated with all of the variables, namely, presence of meaning ( $r=-0.42, p<0.001)$, search for meaning $(r=0.49, p<0.001)$, and with psychological hardiness $(r=-0.73, p<0.001)$. One hierarchical multiple regression analysis was conducted to examine how well-meaning in life dimensions and hardiness predict death anxiety after controlling for age, gender, and the presence of psychiatric diagnosis. As seen in Table 4, the predictor variables were entered in three steps. The presence of diagnosis, gender, and age was entered as control variables in the first step in the regression model. The results reveal that the first model and multiple regression coefficient was significant for age, gender, and presence of diagnosis on death anxiety $(F(3$, $65)=61.219, p<0.001, R=0.86, p<0.001)$. These variables explained $74 \%$ of the variance in death anxiety. Meaning in life dimensions (presence and search for meaning) were entered as a second step that indicated the model and multiple regression coefficient were also significant $(F(5$, $63)=43.034, p<0.001 ; R=0.88, p<0.001)$. After statistically controlling the effects of age, gender, and diagnosis, only presence of meaning added a small but significant contribution to the model $(F$ change $=4.857, p<0.05, t=-2.149$, $\beta=-0.15, p<0.05)$ and this variable resulted in a significant increase in explained variance $\left(R^{2}\right.$ change $\left.=0.035\right)$. Finally, hardiness was entered as the third step. Nevertheless, this model was not significant $(F(6,62)=36.408, p>0.05)$ and did not contribute to a significant proportion of the variance.

\section{Discussion}

The first aim of this study was to explore whether death anxiety, meaning in life dimensions, i.e. presence and search for meaning, and psychological hardiness differ between a GAD sample compared with a non-anxious control group.
The second aim was to investigate the specific contributory roles of meaning in life dimensions and hardiness in predicting death anxiety scores while statistically controlling for age, gender, and the diagnostic difference. Regarding the first aim, we found that individuals with GAD had significantly lower scores on the presence of meaning and hardiness. In contrast, they had higher scores on death anxiety and the search for meaning. Regarding the second aim, the findings revealed that all the variables were associated with each other, and, while statistically controlling for gender, age, and diagnosis, the presence of meaning was the only significant ingredient in the prediction of death anxiety, suggesting a unique relationship between the presence of meaning and death anxiety.

\section{Worry Themes of the Participants with GAD}

Even though we were unable to statistically collect the intensity, frequency, or contents of worry domains of GAD individuals from the clinical interviews, in general, we confirmed that "uncontrollable worry" (Barlow, 1988) and "worry about worry" (Wells, 1995, 1999, 2005) with somatic complaints are the central features of our GAD sample. Worrying can be a compensation method for not dealing with primary or radical issues, particularly interpersonal conflicts (Borkovec et al., 2002). Minor matters can become significant sources of worry that produce greater worry; due to controlling the severity, a couple of participants engaged in reassurance-seeking behaviors to comfort themselves. Likewise, excessive reassurance-seeking was found to be very prevalent, especially in a young (the mid-30 s) Turkish individuals with GAD compared to the older group ( $\leq 65$ years) (Altunoz et al., 2018). The presence of somatic complaints, reassurance-seeking behaviors, poor attentional control and exaggerated attention on minor issues, hypervigilance, and negative appraisals of neutral subjects as well
Table 4 Summary of hierarchical regression analysis of presence of diagnosis, gender, age, meaning in life dimensions, and hardiness in Death anxiety scores

\begin{tabular}{|c|c|c|c|c|c|c|}
\hline \multirow[t]{2}{*}{ Steps } & \multicolumn{6}{|c|}{ Death Anxiety } \\
\hline & $\overline{\Delta \mathrm{R}^{2}}$ & $\beta$ & $\mathrm{p}$ & $\mathrm{b}\left(\mathrm{SE}_{\mathrm{b}}\right)$ & $95 \%$ C.I. for $b$ & $\operatorname{Adj~} R^{2}$ \\
\hline Step 1 & .74 & & & & & \\
\hline $\begin{array}{l}\text { Diagnoses (Anxiety Disorder }=1 \text {, } \\
\text { Control }=0 \text { ) }\end{array}$ & & .85 & .001 & $8.37(.62)$ & $7.13-9.61$ & .73 \\
\hline Gender $($ female $=0$, male $=1)$ & & -.08 & .189 & $-.86(.65)$ & $-2.16-.43$ & \\
\hline Age & & .02 & .764 & $.01(.04)$ & $-.06-.08$ & \\
\hline Step 2 & .04 & & & & & .77 \\
\hline Presence & & -.15 & .035 & $-.11(.05)$ & $-.21-.01$ & \\
\hline Search & & .09 & .229 & $.05(.04)$ & $-.03-.14$ & \\
\hline Step 3 & .01 & & & & & .78 \\
\hline Hardiness & & -.20 & .223 & $-.09(.07)$ & $-25-.06$ & \\
\hline
\end{tabular}

Note: $\Delta \mathrm{R}^{2}=$ Change in $\mathrm{R}^{2} ; \mathrm{b}=$ Unstandardized beta; $\mathrm{SE}_{\mathrm{b}}=$ Standard error of unstandardized beta; $\beta=$ standardized beta; $95 \%$ C.I. $=$ Confidence Interval at $95 \%$ level 
as catastrophic metacognitions about worry that we obtained from the participants are indeed parallel with the clinical model of GAD (Clark, 1986; Wells, 1995, 1999, 2005; see a meta-analysis of Covin et al., 2008). The recent findings have shown that individuals with GAD have a higher frequency of worry, a greater number of different worrying issues, particularly daily hassles, lower subjective controllability, more accompanying somatic symptoms, more distress, and a lower threshold to start worrying (Hirsch et al., 2013; Hoyer et al., 2001; Wells, 2005).

According to conservation of resources theory (Hobfoll, 1989, 2002, 2011), people strive to conserve and build resources due to using them for encounters with adverse events. Hobfoll (1989) suggested four sources: 1) objects are tangible resources such as having a secure physical building/ house 2) Conditions are resources to the extent that they are valued and sought after. For example, having a job, being married, or building a meaningful life. 3) Personal characteristics such as optimism, psychological hardiness, resilience, self-esteem, and a higher IQ for coping with stress. 4) Energies such as time, money, effort, and knowledge. Thus, having a safe environment in a satisfying relationship with greater personal resilience qualities with time and money are the best resources to protect people from the devastating impacts of adversities. Correspondingly, socio-demographic factors play a more significant role, especially in developing countries (Uddin et al., 2019) and suburban regions in Western cultures (Dray et al., 2016) in terms of determining the risk and protective conditions, including the capability of handling the stressors, the presence of criminal acts, and substance abuse, level of awareness, knowledge about the disorder, ego strength, emotional and instrumental social support, and help-seeking behaviors or getting medical help or counseling. Since the "stress-diathesis" model (Monroe \& Simons, 1991) suggests that most psychiatric disorders are thought to occur as a result of environmental stressors experienced by susceptible individuals, lack of these resources would lead vulnerability regarding the onset, maintenance, or prognoses of these disorders (Metts et al., 2021).

In support of the above theories and findings, our sample displayed a high anxiety level (mean score of 66.42) and reported worrying more about the family's well-being and potential loss of loved ones, in addition to somatic symptoms. This high score could be related to having relatively fewer resources in terms of socio-demographic characteristics of our participants. As our groups matched for age and gender, the GAD sample differed only in marital and occupational status from the non-anxious control group, consisting mainly of singles and civil servants. Moreover, the current GAD sample comprises $31.6 \%$ of high school graduates additional as elementary school graduates. Considering Hobfoll's theory, lack of work-life and being married in a patriarchal culture rather than educational level must significantly influence the content and increase the intensity or frequency of GAD symptoms. Parallel to our finding, several studies on Turkish individuals with GAD have indicated that anxiety is significantly higher in married homemakers or unemployed women with a lesser educational level (8th grade at most), particularly in their mid-30 s (Konkan et al., 2013; Ozcan et al., 2006). Even though particular age is the most consistent factor in GAD's clinical manifestations and worry themes (Golden et al., 2011; Gonçalves \& Byrne, 2012, 2013; Gould \& Edelstein, 2010), some findings displayed that marital, occupational, or financial status provides a more critical resource in GAD. For instance, a late-life GAD was more prevalent in married women with less than high school graduation and annually less than $\$ 10,000$ as a personal income (Miloyan \& Pachana, 2015). Likewise, low income is a significant predictor of GAD, particularly in older adults (Miloyan et al., 2014).

\section{GAD and Death Anxiety}

Regarding the first and main focus of the study, which was to examine whether death anxiety, meaning in life dimensions (presence and search for meaning), and psychological hardiness would show a difference between individuals with GAD or without GAD. The findings revealed that individuals with GAD had greater death anxiety scores than non-anxious individuals. This finding is in agreement with the literature. Since the first research was conducted on the relationship between death anxiety and psychopathology (Lester, 1967, 1990; Templer, 1970, 1976), the factor with the most robust relationship with death anxiety was found to be anxiety disorders (Abdel-Khalek, 2005; Abdel-Khalek \& Tomas-Sabado, 2005; Krause et al., 2015). For instance, Furer et al. (1997) investigated the death anxiety levels among individuals with panic disorder, hypochondriasis, and social phobia with a control group. Individuals with panic disorder reported significantly higher death anxiety than social phobia patients and controls. Similarly, Abdel-Khalek (2005) compared death anxiety levels in non-clinical and clinical samples in Egypt, including anxiety disorders, schizophrenia, and substance abuse, and revealed that the scores of individuals with anxiety disorders were significantly greater than other groups. This finding could be evidence that death anxiety is one of the transdiagnostic constructs in playing a hidden but significant role in the development or maintenance of GAD (see Iverach et al., 2014; Menzies et al., 2019). Since the greatest catastrophe that can happen to a person is the encounter with the reality of one's death, perhaps deep-down vulnerability, worthlessness, or helplessness feelings that stemmed from death awareness unconsciously transformed into the themes of catastrophic thoughts or schemas and presented as somatic complaints in GAD. In support of this premise, we observed extreme and 
pervasive worry in the clinical interviews, characterized by catastrophic cognitions presented with many bodily sensations and somatic complaints. Thus, these somatic symptoms can be an extension or reflection of the "sense of loss" associated with death anxiety (Freud, 1936). Accordingly, empirical research has confirmed the vital link between underlying death anxiety in individuals with health anxiety (Noyes et al., 2002). Likewise, Zuccala and Abbott (2021) suggested that encounters with mortality reminders (mortality salience) heightened physical anxiety symptoms in social anxiety disorder.

Although death anxiety is a universal experience, cultural nuances are worth discussing. For example, a study of US and Kuwaiti undergraduate students revealed that the Kuwaiti sample scored significantly higher than the US sample on all scales (Somatic Symptoms Inventory, Death Anxiety, and Fear of Death Scale). Scores on the somatic symptoms were positively associated with death anxiety scores, suggesting that students that present somatic symptoms are more anxious about death (Abdel-Khalek \& Lester, 2009). Similarly, two samples of undergraduate nursing students from Egypt and Spain were compared to assess the relationship between death and trait anxiety. Spanish participants had significantly lower mean scores than the Egyptian sample (Abdel-Khalek \& Tomas-Sabado, 2005). Similar to our findings, death anxiety and trait anxiety were correlated in both samples. Perhaps culturally, individuals in Middle Eastern were more likely to experience both trait and death anxiety more intensely. This severity may result from significant life stressors, traumatic events, or the troubled geographic-socio-political atmosphere of the Middle East regions, including Turkey.

\section{GAD and Meaning in Life}

Results revealed that individuals with GAD had lower scores on the presence of meaning and higher scores in the search for meaning, indicating that individuals with GAD have less meaning in their lives and thus are more likely to search for more meaning. Indeed, this finding is not surprising. Experiencing a sense of meaning is associated with increased life satisfaction and psychological well-being (Chamberlain \& Zika, 1988; Debats, 1996; Steger \& Kashdan, 2007; Steger et al., 2006), less need for psychotherapy (Battista \& Almond, 1973), less anxiety, greater mental health and religiosity (Shiah et al., 2015; Steger et al., 2006; Steger, \& Frazier, 2005; Steger et al., 2009a, b), and less depression (Volkert et al., 2019). More specifically, according to a study carried out with the adult respondents living in the US, a higher presence of meaning in life was correlated with lower health anxiety, although the search for meaning was found to be negatively associated with health anxiety (Yek et al., 2017). Similarly, in a study conducted with cancer patients, it was found that the global sense of meaning, which predicts psychological well-being, acts as a buffer in the development of anxiety symptoms (Vehling et al., 2011). Consistently, setting a purpose as a part of meaningful life was correlated with positive experiences and significantly contributed to the decrease of anxiety and the relief of the autonomic nervous system's overreaction to emotional stress in a sample of Japanese adults (Ishida \& Okada, 2006). Finally, research conducted on Pakistani individuals with GAD displayed that a sense of meaninglessness in life significantly predicted the intensity of GAD symptoms (Amjad \& Bokharey, 2014).

It is known that individuals with GAD experience many physical, affective, and cognitive symptoms that reduce their quality of life, including a sense of a meaningful life. For instance, individuals with GAD reported greater impairment and less social functioning as well as lower quality of life compared to non-anxious controls, especially in terms of self-esteem, goals, and values, money, work, play, learning, creativity, friends, and relatives (Henning et al., 2007; Wittchen, 2002), which are among the things that make life meaningful. Thus, these findings confirm that a global sense of meaning is an essential protective factor to maintain psychological health. On the other hand, the low scores of meaningfulness may be related to the socioeconomic status of our GAD sample. Research on subjective well-being has shown that happy individuals are successful in many areas of life such as marriage, friendship, income, job performance, and health (Diener, 2000; Lyubomirsky et al., 2005). On the contrary, our GAD sample mainly consisted of relatively housewives or homemakers with a restricted income level compared to non-anxious control individuals. These characteristics may reduce the perception of a meaningful life; for instance, at least a work-life balance provides a basis for identity, security, independence, and social network that lead to a meaningful life and psychological health (Lyubomirsky et al., 2005). As discussed earlier, the general worry theme of the participants was found to be associated with the wellbeing of themselves and their family members. This content might imply that "family" is the most significant meaning source for this GAD sample that leads them to feel too much worry and fear to lose at the same time. Even though "family" and "the relationships" were the most effective tools to garner meaning for everyone (Debats, 1999; Grouden \& Jose, 2014; Martela \& Steger, 2016; Schnell, 2009; Steger et al., 2013), there still might be other ways to experience a meaningful life such as living through principles, beliefs or values, meaningful career, harmony with nature, materialistic habits, self-development/growth opportunities, creativity, and a healthy life (Schnell, 2009; Wong, 2008, 2017).

In terms of the relationship between a sense of meaning and socio-demographic status, there are inconsistent findings in different cultures regarding the role of socio-demographic variables such as gender, age, education, finance, and marital 
status. Some of the studies did not reveal any significant differences (Chika Chukwuorji et al., 2019; Naghiyaee et al., 2020; Steger et al., 2006); conversely, some of them indicated the opposite. For instance, less meaning was observed in older Italian males (Volkert, 2019) and in Brazilian single people rather than married ones (Damásio \& Koller, 2015), while more meaning was obtained in elders and parents with at least one child in Switzerland (Costanza et al., 2020), older married women with children with the highest educational level in Denmark (Pedersen et al., 2018), and women in various Western, Middle Eastern, and Asian countries (Steger, Oishi, et al., 2009a, b). In sum, among all the variables, age plays a more consistent role, suggesting that presence of meaning scores are generally higher in later life stages (+65 years) (Reker, 2005; Steger, Oishi, et al., 2009a, b), and older people are more likely to find a standard of living and community activities as more meaningful (Bar-Tur et al., 2001; Grouden \& Jose, 2014), while younger people are more likely to find personal growth opportunities as a source. In the future, meaning sources with different sociodemographic participants in different clinical samples may be a fertile topic on which to conduct research.

\section{GAD and Psychological Hardiness}

Similar to meaningfulness, psychological hardiness scores were found to be lower in participants with GAD when compared to non-anxious individuals. Nevertheless, it is difficult to infer whether low hardiness is a risk factor for the onset of GAD or whether being GAD itself lowers the hardiness scores in the long run. Hardiness is a personality trait or a set of attitudes that includes three dimensions: control, commitment, and challenges that affect the attitudes, beliefs, cognitive interpretations or appraisals, emotions, and behaviors in response to adverse events (Kobasa et al., 1982). Individuals with hardiness are more likely to cope better with stress, try to control and predict the forthcoming events, commit themselves to goals, and are less likely to give up (Maddi, 2004). They choose a future that includes many of unknown or unfamiliar risks instead of past ruminations because they can bear with this uncertainty and potential collapses. Conversely, individuals with low hardiness are more sensitive to life adversities that decrease their psychological immune systems. Accordingly, Kobasa et al. (1985) found that hardiness was a stronger predictor of illness than the positive effects of exercise and social support. Similarly, Saxena (2015) showed among Indian college students and Ahmadi Gatab and Vahedi Ghajari (2013) showed among Iranian college students that hardiness is positively correlated with various mental health indicators, including self-efficacy and self-esteem.

Undoubtedly, individuals with GAD also try to control events and struggle with problems, but, in the face of a problem, they are more likely to appraise the events as negative, unsolvable, and pessimistic (Davey, 1994; Koerner \& Dugas, 2008; Ladouceur et al., 1998) and start to worry (Borkovec et al., 2004). They use worrying as a cognitive effort of problem-solving or an attempt to gain back the sense of control, very similar to rumination (NolenHoeksema et al., 2008; Stöber et al., 2000). The more they worry, the more helpless they feel for worrying (worry about worry) this time (Wells, 2005). The uncontrollability of worry becomes a more pervasive and broader issue on its own. Since hardiness has been negatively correlated with all domains of worry such as lack of confidence, aimless future, financial shortcomings, and work incompetence (Kowalski \& Schermer, 2019), individuals with GAD can be given hardiness skills as coping strategies such as active problem solving, social support, positive reinterpretation, and cognitive flexibility (Crowley \& Hobdy, 2003).

In addition, socio-demographic characteristics play a role in the application of coping methods in daily life. Accordingly, individuals with more personal and environmental resources were more likely to use active coping and less likely to use avoidant coping (Holahan \& Moos, 1987). Likewise, Caplan and Schooler (2007) suggested that lower socioeconomic status is associated with greater use of emotion-focused financial coping and less use of problemfocused financial coping. Low socio-demographic status also reduces self-confidence, making it less likely to implement adaptive financial coping processes and causes a double disadvantage. Taken together, having a diagnosis of GAD with limited socioeconomic status and lack of work-life and relationship conflicts may decrease the self-awareness and problem-solving manners that would contribute to the severity of their problems.

\section{Conceptual Predictors of Death Anxiety}

Regarding the second aim, which were to investigate the conceptual relationships between study variables and examine the predictive roles of death anxiety in all individuals, respectively, the results revealed that all variables, including death anxiety, meaning in life dimensions, and hardiness were correlated with each other. The presence of meaning was the only significant ingredient in predicting death anxiety when statistically controlling for gender, age, and diagnosis presence, suggesting a unique relationship between the sense of a meaningful life and death anxiety. Nevertheless, its predictive role was relatively small (see Table 4).

Death anxiety is a complex phenomenon that is vulnerable to various personal and social indicators. So far, previous research on death anxiety has concluded that death anxiety is firstly a valid concept (Lester, 1967, 1990; Templer, 1970, 1976; Templer et al., 2006), present in all cultures to different degrees (Abdel-Khalek, 1991; Abdel-Khalek 
\& Lester, 2009; Abdel-Khalek \& Tomas-Sabado, 2005; Suhail \& Akram, 2002; see a meta-review of Pandya \& Kathuria, 2021), and has an inverted U-shaped relationship with religiosity, indicating that highly religious people and non-religious ones have lower scores (see meta-analysis of Jong et al., 2018). This may be related to socio-demographic characteristics, suggesting that females and younger subjects with have higher scores (Fortner et al., 1999; Neimeyer et al., 2004; Thorson \& Powell, 1988), but this is still sensitive to cultural factors (see Dadfar et al., 2021) and is associated with low self-efficacy and external health control orientations (Tang et al., 2002), neuroticism and type A behaviors (Frazier \& Foss-Goodman, 1989), and psychological maturity (Rasmussen \& Brems, 1996) as well as more significant psychological symptoms (Menzies \& Dar-Nimrod, 2017; Menzies \& Menzies, 2020; Menzies et al., 2019; Miller et al., 2012; Öngider \& Özışık Eyüboğlu, 2013).

Although a meaningful life contributes little to explaining death anxiety, the need for meaning can be one of the most protective resources or experience against mortality knowledge (see Tillich, 1952). The underlying fear of non-existence or non-being, meaninglessness, or emptiness leads to psychological distress, anxiety symptoms, and nöogenic neurosis (Frankl, 1967, 1985). Meaning-making or finding meaning, even in the most suffering conditions, through responsibility, deep and genuine relations with family and friends, altruistic behaviors, ability to prioritize tasks, expression of feelings through art, living a life with values, and accepting the current conditions are some ways to maintain psychological health (see Dursun \& Söylemez, 2020; Shakespeare-Finch \& Lurie-Beck, 2014; Tedeschi \& Calhoun, 2004; Wong, 2000, 2017). Even though previous non-clinical samples found inconsistent results on the roles of meaning dimensions (presence of meaning and search for meaning) in predicting death anxiety (Lyke, 2013; Yüksel et al., 2017), our findings are compatible with mainstream theories (Baumeister, 1991; Becker, 1973; Frankl, 1985; Yalom, 2008) and some research (Blazer, 1973; Ozanne et al., 2013; Rappaport et al., 1993). Death anxiety and need for meaning are two primary, interactive and bipolar motives that determine the level of psychological health (Wong \& Tomer, 2011) because the feeling of not having found the meaning of life yet makes an individual feel highly worried that time will run out on achieving some goals or tasks in life. Thus, individuals with meaningful lives have less unfinished business and experience fewer adverse effects, particularly resentment, loneliness, unfairness, desperation, guilt, and shame when aging. Thus they are more likely to experience death acceptance than anxiety or fear (Blazer, 1973; Erikson, 1982; Wong, 2000; Wong \& Tomer, 2011). Moreover, death denial or suppressing death awareness consciously or unconsciously displays itself in various symptoms such as anxiety, worry, depression, sorrow, distress, and many somatic complaints (Iverach et al., 2014; Yalom, 2008). Thus, meaning-making or meaning management processes can be protective against GAD development, treatment, or prognosis (Wong, 2000, 2008). For instance, a recent systematic review of psychological interventions among patients with advanced cancer concluded that a sense of meaning-making has the most beneficial effect on death attitudes and general well-being among treatments focusing on existential themes such as meaning, dignity, relationships, and spiritual well-being (Grossman et al., 2018). Qualitative research has shown that finding meaning despite having a disease decreases death anxiety and intolerance of uncertainty among ALS patients suggesting that meaning can be found through sincere relationships with family and friends, the act of giving support and receiving help, a sense of having a life of their own, and accepting the present with a new life perspective, which is deeper when material things and daily hassles are no longer in focus (Ozanne et al., 2013).

Surprisingly, neither search for meaning nor hardiness predicted death anxiety. We expect that searching for meaning raises an individual's anxiety about running out of time to live life fully. However, conceptually, search for meaning is not equal to meaninglessness; instead, it is an active search or seeking more meaning and a copying process (Steger \& Park, 2012). Perhaps, death anxiety was not directly related to an active search for further meaning that has often inconsistent findings resulting from cultural differences (Steger et al., 2008a, 8b). Regarding hardiness, it is also an unexpected finding. Theoretically, hardiness or existential courage is a kind of resilience concept associated with better health, stamina, and performance under various stressful conditions (Bartone et al., 2008; Maddi, 2004). Individuals with hardiness skills tend to be future-minded, enjoy novelty, take risks, and are less likely to withdraw when they get frustrated. They like being challenged and accept ambiguous events as they are. Nevertheless, choosing the future instead of the past takes courage because it brings a potential change in routines and risks of failure leading to greater ontological anxiety (Maddi, 2004). That is why we expected that hardiness scores might have significantly predicted death anxiety. This unexpected finding could be first related to the dimensions of hardiness as a concept. As is known, hardiness refers to a motivational perspective to turn stressful events into potential gains or opportunities through control, commitment, and challenging skills that are helpful for psychological health confirmed by the current research. However, these three skills need to be used in a balance or synergistic manner; otherwise, they can lead to a highly narcissistic, pragmatic, insecure, and mortal world. For example, people with a high control dimension may display very control-seeking behaviors in their interactions with others, which can lead to narcissistic tendencies, or they may dedicate themselves to a goal that can be exceedingly hurtful 
to others, or when they try to avoid powerlessness and passivity, they might put themselves in too much danger instead of learning from the past experience (Maddi, 2002). Moreover, we used total scores in this study because the Turkish version has a different factor structure than the original (see Durak, 2002). We could not examine which dimension contributed most to the total score. Perhaps in the future, the role of dimensions can be clarified with cross-cultural studies. Furthermore, hardiness is debatable as to whether it is a unitary or multifaceted construct, stable trait, or an umbrella term for certain attitudes or skills (see Lambert \& Lambert, 1999). At least recent findings suggest that the function or direction of hardiness has been changing from existential matters to business or work-life, especially for the prevention of burn-out, development of leadership, and military/officers training (Bagley et al., 2018; Hystad et al., 2011; Lambert et al., 2003; Nguyen et al., 2012; Sandvik et al., 2020; Sezgin, 2009). Secondly, death anxiety, an ontological part of being human (Heidegger, 1953; Tillich, 1952), is a complex phenomenon that includes both future and past features. It is past because it is latent, naturally present, and a given entity in all human beings. It is future-oriented because death and anxiety are about the future. Thus, death anxiety and hardiness may be distinct or unrelated concepts, or at least our participants may have understood the past characteristics of death anxiety rather than the future of hardiness.

Undoubtedly, some limitations should be acknowledged; first, our sample size is minimal for both groups, resulting in limited external validity of the results. Second, this was a cross-sectional study; certainly, the best prognosis or course of the disorders would be observed with longitudinal or qualitative studies, including new techniques such as online photovoice (OPV), which allows individuals to express their thoughts and feelings through their senses (see Tanhan \& Strack, 2020).

\section{Implications}

These findings may have several theoretical and practical implications. First of all, current empirically valid treatment models or protocols of GAD have originated from either behavioral or cognitive-behavioral schools (BT/CBT, see a meta-analysis of Covin et al., 2008), and more recently from acceptance and commitment therapy (ACT, Hayes, 2004; Roemer \& Orsillo, 2002). While these models differ to some extent, they share an underlying commonality in their particular focus on the cognitive, emotional, or experiential factors that involved in vulnerability, onset, and maintenance of the disorder (see a review of Behar et al., 2009; Locke et al., 2015). These most common models can be integrated with more existential factors such as death anxiety and enriched with more personal resources such as meaningful life and hardiness skills.
In terms of death anxiety, as in our GAD example, somatic complaints supported with worry themes can be related to the feeling of loss, loneliness, worthlessness, and helplessness schemas, which are part of a patriarchal culture, can be associated with deep-down death or ontological anxiety. These core schemas of recurrent anxiety themes can be discussed and associated with death anxiety or fear of their own or loved ones' non-existence. Thus, the client can be reminded that the most significant dilemma in life is to face one's own non-being, namely death. The only exit to solve this dilemma is to understand and accept the ambiguity of life and try to find possible solutions for the events that lead to anxiety (see Tanhan, 2019). During the stages of psychoeducation on the GAD model and cognitive restructuring, gaining mental flexibility, and facilitating the clients to see the threats as challenges, the clients can acquire to broaden their perspectives and reframe their adverse events with knowledge of mortality. Death acceptance with egointegrity can be a significant way to accept the uncertainty of life (Erikson, 1982; Wong, 2000). A reasonable degree of acceptance of death frees us from anxiety and gives us more vitality, purpose, and meaning to life.

In terms of meaningful life, the basic fears of individuals with GAD can reflect the fear of losing meaning in their lives. Therefore, in this step, constructing the global meanings in life with the help of re-defining life goals, making sense of the events, perception of self and, the significance of life, particularly during adversities, can be emphasized (Park, 2010; Wong, 2008). Additionally, meaning management methods (see Wong, 2017) can also be used in decreasing the misinterpretation of bodily sensations and feelings. For example, the client can be taught that internal states such as uncontrollable worry are not a permanent state that defines the person herself. This misinterpretation reinforces the avoidance of worry and inhibits individuals from engaging in meaningful activities that cause more distress and, in the long run, it turns into a vicious cycle (Roemer \& Orsillo, 2002). On the contrary, valued or meaningful actions are the necessary experience to stay in the moment, be compassionate, and rebuild a global meaning. Since anxiety is about living the future rather than the present (Borkovec, 2002) and worrying sometimes includes possible future events, clients can be taught to have present-moment attention or mindfulness skills that are significantly lower in individuals with GAD (Roemer et al., 2008, 2009).

Lastly, acquiring hardiness skills such as being able to challenge, commit, and control stressful situations can be integrated into cognitive restructuring and improving the problem-orientation of individuals with GAD (Kobasa et al., 1982). Many individuals with GAD experience worry when they will fail to solve a problem; this pessimism and lack of self-efficacy leads them to cognitively avoid the solution and maintenance of worry (Koerner \& Dugas, 2008). Discussing 
the dysfunctional attitudes about problem-solving with the discrimination of events, thoughts, and surrounding feelings can be enhanced with a perspective challenge and an opportunity to grow. Additionally, positive self-talk about self-efficacy and positive orientation to coping strategies can be facilitated to decrease worrying about minor issues to escape significant problems, as the results showed that worrying was experienced primarily as verbal thought rather than imagination (Behar et al., 2005).

\section{Conclusion}

In conclusion, this study confirms that death anxiety may be one of the transdiagnostic constructs for a diagnosis of GAD that increased vulnerability to onset or maintenance (see Iverach et al., 2014; Menzies et al., 2019). However, the socioeconomic disadvantages of GAD participants may also influence the clinical manifestation, the severity of GAD, and the coping mechanisms needed for prognosis (see Ansseau et al., 2008; Hobfoll, 2002, 2011). In addition to death anxiety, we also found that the presence of meaning and hardiness scores were significantly lower in participants with GAD. Both prevention and intervention studies might increase these resilience sources to increase psychological immunity and give a place to the concept of death anxiety, particularly in participants with greater somatic manifestations. Meaning-making or management through gathering diverse sources may be the most important solution for the implicit pressure of death anxiety. This study was not supported by any funding source. The datasets generated during and/or analyzed during the current study are available from the corresponding author on reasonable request.

\section{Declarations}

Conflict of Interests Authors have no conflict of interest.

Human Studies All procedures performed in studies involving human participants were in accordance with the ethical standards of the institutional and/or national research committee and with the 1964 Helsinki declaration and its later amendments or comparable ethical standards.

\section{References}

Abdel-Khalek, A. M. (1991). Death anxiety among Lebanese samples. Psychological Reports, 68(3), 924-926. https://doi.org/10.2466/ pr0.1991.68.3.924

Abdel-Khalek, A. M. (2005). Death anxiety in clinical and non-clinical groups. Death Studies, 29(3), 251-259. https://doi.org/10.1080/ 07481180590916371

Abdel-Khalek, A. M., \& Lester, D. (2009). Death anxiety as related to somatic symptoms in two cultures. Psychological Reports, 105(2), 409-410. https://doi.org/10.2466/PR0.105.2.409-410
Abdel-Khalek, A. M., \& Tomás-Sábado, J. (2005). Anxiety and death anxiety in Egyptian and Spanish nursing students. Death Studies, 29(2), 157-169. https://doi.org/10.1080/074811805909061 74

Ahmadi Gatab, T., \& Vahedi Ghajari, A. (2013). Comparison of Psychological Hardiness with Mental Health Among Male \& Female Students. European Psychiatry, 28, 1-1. https://doi. org/10.1016/S0924-9338(13)77464-9

Altunoz, U., Kokurcan, A., Kirici, S., Bastug, G., \& Ozel-Kizil, E. T. (2018). Clinical characteristics of generalized anxiety disorder: older vs young adults. Nordic journal of psychiatry, 72(2), 97-102. https://doi.org/10.1080/08039488.2017.1390607

American Psychiatric Association. (2013). Diagnostic and Statistical Manual of Mental Disorders DSM-5 (5th ed.). American Psychiatric Association Publishing.

Amjad, F., \& Bokharey, I. Z. (2014). The impact of spiritual wellbeing and coping strategies on patients with generalized anxiety disorder. Journal of Muslim mental health, 8(1). https://doi. org/10.3998/jmmh.10381607.0008.102

Ansseau, M., Fischler, B., Dierick, M., Albert, A., Leyman, S., \& Mignon, A. (2008). Socioeconomic correlates of generalized anxiety disorder and major depression in primary care: The GADIS II study (Generalized Anxiety and Depression Impact Survey II). Depression and Anxiety, 25(6), 506-513. https:// doi.org/10.1002/da.20306

Arndt, J., Routledge, C., Cox, C. R., \& Goldenberg, J. L. (2005). The worm at the core: A terror management perspective on the roots of psychological dysfunction. Applied and Preventive Psychology, 11(3), 191-213. https://doi.org/10.1016/j.appsy. 2005.07.002

Bagley, C., Abubaker, M., \& Sawyerr, A. (2018). Personality, worklife balance, hardiness, and vocation: A typology of nurses and nursing values in a special sample of English hospital nurses. Administrative Sciences, 8(4), 79. https://doi.org/10.3390/admsc i8040079

Bandelow, B., \& Michaelis, S. (2015). Epidemiology of anxiety disorders in the 21st century. Dialogues in clinical neuroscience, 17(3), 327-335. https://doi.org/10.31887/DCNS.2015.17.3/ bbandelow

Bandelow, B., Michaelis, S., \& Wedekind, D. (2017). Treatment of anxiety disorders. Dialogues in clinical neuroscience, 19(2), 93-106. https://doi.org/10.31887/DCNS.2017.19.2/bbandelow

Barlow, D. H. (1988). Anxiety and its disorders: The nature and treatment of anxiety and panic. The Guilford Press.

Bartone, P. T., Roland, R. R., Picano, J. J., \& Williams, T. J. (2008). Psychological hardiness predicts success in US Army Special Forces candidates. International Journal of Selection and Assessment, 16(1), 78-81. https://doi.org/10.1111/j.1468-2389.2008. 00412.x

Bar-Tur, L., Savaya, R., \& Prager, E. (2001). Sources of meaning in life for young and old Israeli Jews and Arabs. Journal of Aging Studies, 15(3), 253-269. https://doi.org/10.1016/S0890-4065(01) 00022-6

Battista, J., \& Almond, R. (1973). The development of meaning in life. Psychiatry, 36(4), 409-427. https://doi.org/10.1080/00332747. 1973.11023774

Baumeister, R. F. (1991). Meanings of Life. The Guildford Press.

Beck, A. T., Laude, R., \& Bohnert, M. (1974). Ideational components of anxiety neurosis. Archives of General Psychiatry, 31, 319325. https://doi.org/10.1001/archpsyc.1974.01760150035005

Beck, A. T., Rush, A. J., Shaw, B. F., \& Emery, G. (1979). Cognitive therapy of depression: A treatment manual. The Guilford Press.

Beck, A. T., Ward, C. H., Mendelson, M., Mock, J., \& Erbaugh, J. (1961). An inventory for measuring depression. Archives of General Psychiatry, 4, 561-571.

Becker, E. (1973). The denial of death. Simon \& Schuster Press. 
Behar, E., Zuellig, A. R., \& Borkovec, T. D. (2005). Thought and imaginal activity during worry and trauma recall. Behavior Therapy, 36(2), 157-168. https://doi.org/10.1016/S00057894(05)80064-4

Behar, E., DiMarco, I. D., Hekler, E. B., Mohlman, J., \& Staples, A. M. (2009). Current theoretical models of generalized anxiety disorder (GAD): Conceptual review and treatment implications. Journal of Anxiety Disorders, 23(8), 1011-1023. https:// doi.org/10.1016/j.janxdis.2009.07.006

Blazer, J. A. (1973). The relationship between meaning in life and fear of death. Psychology: A journal of human behavior, 10(2), 33-34.

Bonanno, G. A. (2004). Loss, Trauma, and Human Resilience: Have We Underestimated the Human Capacity to Thrive After Extremely Aversive Events? American Psychologist, 59(1), 20-28. https://doi.org/10.1037/0003-066X.59.1.20

Borkovec, T. D. (2002). Life in the future versus life in the present. Clinical Psychology: Science and Practice, 9(1), 76-80. https://doi.org/10.1093/clipsy.9.1.76

Borkovec, T. D., Alcaine, O. M., \& Behar, E. (2004). Avoidance Theory of Worry and Generalized Anxiety Disorder. In R. G. Heimberg, C. L. Turk, \& D. S. Mennin (Eds.), Generalized anxiety disorder: Advances in research and practice (pp. 77-108). The Guilford Press.

Borkovec, T. D., Newman, M. G., Pincus, A. L., \& Lytle, R. (2002). A component analysis of cognitive-behavioral therapy for generalized anxiety disorder and the role of interpersonal problems. Journal of Consulting and Clinical Psychology, 70(2), 288-298. https://doi.org/10.1037/0022-006X.70.2.288

Bower, J. E., Kemeny, M. E., Taylor, S. E., \& Fahey, J. L. (1998). Cognitive processing, discovery of meaning, CD4 decline, and AIDS-related mortality among bereaved HIV-seropositive men. Journal of Consulting and Clinical Psychology, 66(6), 979-986. https://doi.org/10.1037/0022-006X.66.6.979

Caplan, L. J., \& Schooler, C. (2007). Socioeconomic status and financial coping strategies: The mediating role of perceived control. Social Psychology Quarterly, 70(1), 43-58. https:// doi.org/10.1177/019027250707000106

Caras, G. W. (1995). The relationships among psychological separation, the quality of attachment, separation anxiety and death anxiety. Dissertation Abstracts International, Section b: The Sciences and Engineering, 56, 3436.

Chait, I. (1998). Terror of dying: Separation anxiety and the potential for psychic change in the psychotherapy of a 7 year-old boy. Psycho-Analytic Psychotherapy in South Africa, 6, 29-40. https://hdl.handle.net/10520/EJC88441. Accessed 27 May 2021

Chamberlain, K., \& Zika, S. (1988). Religiosity, life meaning and wellbeing: Some relationships in a sample of women. Journal for the Scientific Study of Religion, 27(3), 411-420. https://doi. org/10.2307/1387379

Chatard, A., Pyszczynski, T., Arndt, J., Selimbegovic, L., Konan, P. N., \& Van der Linden, M. (2012). Extent of trauma exposure and PTSD symptom severity as predictors of anxiety-buffer functioning. Psychological Trauma: Theory, Research, Practice, and Policy, 4, 47-55. https://doi.org/10.1037/a0021085

Cheung, M. C., Dennis, I., Easthope, Y., Werrett, J., \& Farmer, S. (2005). A multiple-indicator multiple-cause model for posttraumatic stress reactions: Personality, coping, and maladjustment. Psychosomatic Medicine, 67, 251-259. https://doi.org/ 10.1097/01.psy.0000155675.56550.5f

Chika Chukwuorji, J., Ekpedoho, E. A., Ifeagwazi, C. M., Iorfa, S. K., \& Nwonyi, S. K. (2019). Psychometric properties of the Meaning in Life Questionnaire-Hausa version among internally displaced persons in Nigeria. Transcultural Psychiatry, 56(1), 103-122. https://doi.org/10.1177/1363461518794218
Clark, D. M. (1986). A cognitive approach to panic. Behaviour Research and Therapy, 24(4), 461-470. https://doi.org/10.1016/ 0005-7967(86)90011-2

Covin, R., Ouimet, A. J., Seeds, P. M., \& Dozois, D. J. (2008). A metaanalysis of CBT for pathological worry among clients with GAD. Journal of Anxiety Disorders, 22(1), 108-116. https://doi.org/10. 1016/j.janxdis.2007.01.002

Costanza, A., Baertschi, M., Richard-Lepouriel, H., Weber, K., Pompili, M., \& Canuto, A. (2020). The presence and the search constructs of meaning in life in suicidal patients attending a psychiatric emergency department. Frontiers in Psychiatry, 11, 327-334. https://doi.org/10.3389/fpsyt.2020.00327

Crowley, B. J., \& Hobdy, J. (2003). Psychological hardiness and adjustment to life events in adulthood. Journal of Adult Development, 10(4), 237-248. https://doi.org/10.1023/A:1026007510134

Dadfar, M., Lester, D., \& Abdel-Khalek, A. M. (2021). Validity and reliability of the Farsi version of the Death Anxiety Scale with nurses. Illness, Crisis \& Loss, 29(4), 340-353. https://doi.org/ 10.1177/1054137318810232.

Damásio, B. F., \& Koller, S. H. (2015). Meaning in Life Questionnaire: Adaptation process and psychometric properties of the Brazilian version. Revista Latino Americana De Psicología, 47(3), 185-195. https://doi.org/10.1016/j.rlp.2015.06.004

Davey, G. C. (1994). Worrying, social problem-solving abilities, and social problem-solving confidence. Behaviour Research and Therapy, 32(3), 327-330. https://doi.org/10.1016/0005-7967(94) 90130-9

Debats, D. L. (1996). Meaning in life: Clinical relevance and predictive power. British Journal of Clinical Psychology, 35(4), 503-516. https://doi.org/10.1111/j.2044-8260.1996.tb01207.x

Debats, D. L. (1999). Sources of meaning: An investigation of significant commitments in life. Journal of Humanistic Psychology, 39(4), 30-57. https://doi.org/10.1177/0022167899394003

Diener, E. (2000). Subjective well-being: The science of happiness and a proposal for a national index. American Psychologist, 55(1), 34-43. https://doi.org/10.1037/0003-066X.55.1.34

Dolcos, S., Hu, Y., Iordan, A. D., Moore, M., \& Dolcos, F. (2016). Optimism and the brain: Trait optimism mediates the protective role of the orbitofrontal cortex gray matter volume against anxiety. Social Cognitive and Affective Neuroscience, 11(2), 263-271. https://doi.org/10.1093/scan/nsv106

Dray, J., Bowman, J., Freund, M., Campbell, E., Hodder, R. K., Lecathelinais, C., \& Wiggers, J. (2016). Mental health problems in a regional population of Australian adolescents: Association with socio-demographic characteristics. Child and Adolescent Psychiatry and Mental Health, 10(1), 1-11. https://doi.org/10.1186/s13034-016-0120-9

Durak, M. (2002). Predictive role of hardiness on psychological symptomatology of university students experienced earthquake. (Unpublished Master Thesis). Ankara, Turkey: Middle East Technical University Social Sciences Institute.

Dursun, P. (2012). The role of meaning in life, optimism, hope and coping styles in subjective wellbeing (Unpublished Dissertation). Ankara, Turkey: Middle East Technical University Social Sciences Institute.

Dursun, P., \& Alyağut, P. (2020). Meaning in/of Life: Discovery, Invention or Both? Cyprus Turkish journal of psychiatry and psychology, 2(3), 180-186. https://doi.org/10.35365/ctjpp.20.02.25

Dursun, P., \& Söylemez, İ. (2020). Posttraumatic Growth: A Comprehensive Evaluation of the Recently Revised Model. [Travma Sonrası Büyüme: Gözden Geçirilmiş Son Model ile Kapsamlı Bir Değerlendirme]. Turkish journal of psychiatry, 31(1), 59-69. https://doi.org/10.5080/u23694

Erikson, E. H. (1982). The life cycle completed. Norton.

Eshbaugh, E., \& Henninger, W. (2013). Potential Mediators of the Relationship Between Gender and Death Anxiety. Individual Differences Research, 11(1), 22-30. 
Ezazi Bojnourdi, E., Ghadampour, S., Moradi Shakib, A., \& Ghazbanzadeh, R. (2020). Predicting Corona Anxiety based on Cognitive Emotion Regulation Strategies, Health Hardiness and Death Anxiety in Diabetic Patients. Iranian Journal of Psychiatric Nursing, 8(2), 34-44.

Fortner, B. V., Robert, A., \& Neimeyer, B. (1999). Death anxiety in older adults: A quantitative review. Death Studies, 23(5), 387-411. https://doi.org/10.1080/074811899200920

Frankl, V. E. (1967). Logotherapy and existentialism. Psychotherapy: Theory. Research, and Practice, 4(3), 138-142.

Frankl, V. E. (1985). Man's Search for Meaning. Washington Square Press.

Frazier, P. H., \& Foss-Goodman, D. (1989). Death anxiety and personality: Are they truly related? OMEGA-Journal of Death and Dying, 19(3), 265-274. https://doi.org/10.2190/ 141T-Q32F-LPPD-EY3W

Freud, S. (1925). Thoughts for the times on war and death. Hogart Press.

Freud, S. (1936). The Problem of Anxiety. Norton Publishing.

Furer, P., Walker, J. R., Chartier, M. J., \& Stein, M. B. (1997). Hypochondriacal concerns and somatization in panic disorder. Depression and Anxiety, 6, 78-85. https://doi.org/10.1002/ (SICI) 1520-6394(1997)6:2\%3c78::AID-DA4\%3e3.0.CO;2-1

Golden, J., Conroy, R. M., Bruce, I., Denihan, A., Greene, E., Kirby, M., \& Lawlor, B. A. (2011). The spectrum of worry in the community-dwelling elderly. Aging \& Mental Health, 15(8), 985994. https://doi.org/10.1080/13607863.2011.583621

Gonçalves, D. C., \& Byrne, G. J. (2012). Interventions for generalized anxiety disorder in older adults: Systematic review and metaanalysis. Journal of Anxiety Disorders, 26(1), 1-11. https://doi. org/10.1016/j.janxdis.2011.08.010

Gonçalves, D. C., \& Byrne, G. J. (2013). Who worries most? Worry prevalence and patterns across the lifespan. International Journal of Geriatric Psychiatry, 28(1), 41-49. https://doi.org/10.1002/ gps. 3788

Gould, C. E., \& Edelstein, B. A. (2010). Worry, emotion control, and anxiety control in older and young adults. Journal of Anxiety Disorders, 24(7), 759-766. https://doi.org/10.1016/j.janxdis. 2010.05.009

Greenberg, J., Pyszczynski, T., \& Solomon, S. (1986). The causes and consequences of a need for self-esteem: A terror management theory In Public self and private self (pp. 189-212). Springer Publishing.

Greenberg, J., Pyszczynski, T., Solomon, S., Rosenblatt, A., Veeder, M., Kirkland, S., \& Lyon, D. (1990). Evidence for terror management theory II: The effects of mortality salience on reactions to those who threaten or bolster the cultural worldview. Journal of Personality and Social Psychology, 58(2), 308-318. https://doi. org/10.1037/0022-3514.58.2.308

Greenberg, J., Pyszczynski, T., Solomon, S., Pinel, E., Simon, L., \& Jordan, K. (1993). Effects of self-esteem on vulnerability-denying defensive distortions: Further evidence of an anxiety-buffering function of self-esteem. Journal of Experimental Social Psychology, 29(3), 229-251. https://doi.org/10.1006/jesp.1993.1010

Grossman, C. H., Brooker, J., Michael, N., \& Kissane, D. (2018). Death anxiety interventions in patients with advanced cancer: A systematic review. Palliative Medicine, 32(1), 172-184. https://doi. org/10.1177/0269216317722123

Grouden, M. E., \& Jose, P. E. (2014). How do sources of meaning in life vary according to demographic factors? New Zealand Journal of Psychology, 43(3), 29-38.

Hayes, S. C. (2004). Acceptance and commitment therapy, relational frame theory, and the third wave of behavioral and cognitive therapies. Behavior Therapy, 35(4), 639-665. https://doi.org/10. 1016/S0005-7894(04)80013-3
Hayes, A. F. (2017). Introduction to mediation, moderation, and conditional process analysis: A regression-based approach. The Guilford Press.

Heidegger, M. (1953). Being and Time, trans. by Joan Stambaugh. State University of New York Press.

Henning, E. R., Turk, C. L., Mennin, D. S., Fresco, D. M., \& Heimberg, R. G. (2007). Impairment and quality of life in individuals with generalized anxiety disorder. Depression and Anxiety, 24(5), 342-349. https://doi.org/10.1002/da.20249

Herrman, H., Stewart, D. E., Diaz-Granados, N., Berger, E. L., Jackson, B., \& Yuen, T. (2011). What is resilience? The Canadian Journal of Psychiatry, 56(5), 258-265. https://doi.org/10.1177/ 070674371105600504

Hinton, D. E., Park, L., Hsia, C., Hofmann, S., \& Pollack, M. H. (2009). Anxiety disorder presentations in Asian populations: A review. CNS Neuroscience \& Therapeutics, 15(3), 295-303. https://doi.org/10.1111/j.1755-5949.2009.00095.x

Hirsch, C. R., Mathews, A., Lequertier, B., Perman, G., \& Hayes, S. (2013). Characteristics of worry in generalized anxiety disorder. Journal of Behavior Therapy and Experimental Psychiatry, 44(4), 388-395. https://doi.org/10.1016/j.jbtep.2013.03.004

Hisli, N. (1989). A reliability and validity study of Beck Depression Inventory in a university student sample. Journal of Psychology, $6,3-13$.

Hobfoll, S. E. (1989). Conservation of resources: A new attempt at conceptualizing stress. American Psychologist, 44(3), 513-524. https://doi.org/10.1037/0003-066X.44.3.513

Hobfoll, S. E. (2002). Social and psychological resources and adaptation. Review of General Psychology, 6(4), 307-324. https://doi. org/10.1037/1089-2680.6.4.307

Hobfoll, S. E. (2011). Conservation of resource caravans and engaged settings. Journal of Occupational and Organizational Psychology, 84(1), 116-122. https://doi.org/10.1111/j.2044-8325.2010. 02016.x

Holahan, C. J., \& Moos, R. H. (1987). Personal and contextual determinants of coping strategies. Journal of Personality and Social Psychology, 52(5), 946-955. https://doi.org/10.1037/0022-3514. 52.5.946

Hoyer, J., Becker, E. S., \& Roth, W. T. (2001). Characteristics of worry in GAD patients, social phobics, and controls. Depression and Anxiety, 13(2), 89-96. https://doi.org/10.1002/da.1021

Hystad, S. W., Eid, J., \& Brevik, J. I. (2011). Effects of psychological hardiness, job demands, and job control on sickness absence: A prospective study. Journal of Occupational Health Psychology, 16(3), 265-278. https://doi.org/10.1037/a0022904

Ishida, R., \& Okada, M. (2006). Effects of a firm purpose in life on anxiety and sympathetic nervous activity caused by emotional stress: Assessment by psycho-physiological method. Stress and Health: Journal of the International Society for the Investigation of Stress, 22(4), 275-281. https://doi.org/10.1002/smi.1095

Iverach, L., Menzies, R. G., \& Menzies, R. E. (2014). Death anxiety and its role in psychopathology: Reviewing the status of a transdiagnostic construct. Clinical Psychology Review, 34, 580-593. https://doi.org/10.1016/j.cpr.2014.09.002

Jong, J., Ross, R., Philip, T., Chang, S. H., Simons, N., \& Halberstadt, J. (2018). The religious correlates of death anxiety: A systematic review and meta-analysis. Religion, Brain \& Behavior, 8(1), 4-20. https://doi.org/10.1080/2153599X.2016.1238844

Kessler, R. C., \& Wang, P. S. (2008). The descriptive epidemiology of commonly occurring mental disorders in the United States. Annual Review of Public Health, 29, 115-129. https://doi.org/ 10.1146/annurev.publhealth.29.020907.090847

Kobasa, S. C., Maddi, S. R., \& Kahn, S. (1982). Hardiness and health: A prospective study. Journal of Personality and Social Psychology, 42(1), 168-177. https://doi.org/10.1037/0022-3514.42.1.168 
Kobasa, S. C., Maddi, S. R., Puccetti, M. C., \& Zola, M. A. (1985). Effectiveness of hardiness, exercise and social support as resources against illness. Journal of Psychosomatic Research, 29(5), 525-533. https://doi.org/10.1016/0022-3999(85)90086-8

Koerner, N., \& Dugas, M. J. (2008). An investigation of appraisals in individuals vulnerable to excessive worry: The role of intolerance of uncertainty. Cognitive Therapy and Research, 32(5), 619-638. https://doi.org/10.1007/s10608-007-9125-2

Konkan, R., Şenormanci, Ö., Güçlü, O., Aydin, E., \& Sungur, M. Z. (2013). Yaygın Anksiyete Bozukluğu-7 (YAB-7) Testi Türkçe Uyarlaması, Geçerlik ve Güvenirliği. [Validity and Reliability Study for the Turkish Adaptation of the Generalized Anxiety Disorder-7 (GAD-7) Scale]. Archives of neuropsychiatry, 50(1), 53-58.

Kovács, I. K., \& Borcsa, M. (2017). The relationship between anxiety, somatic symptoms and hardiness in adolescence. Romanian Journal of Psychology, 19(2), 42-49. https://doi.org/10.24913/ rjap.19.2.03

Kowalski, C. M., \& Schermer, J. A. (2019). Hardiness, perseverative cognition, anxiety, and health-related outcomes: A case for and against psychological hardiness. Psychological Reports, 122(6), 2096-2118. https://doi.org/10.1177/0033294118800444

Krause, N. (2004). Stressors arising in highly valued roles, meaning in life, and the physical health status of older adults. The Journals of Gerontology Series b: Psychological Sciences and Social Sciences, 59(5), S287-S297. https://doi.org/10.1093/geronb/59.5. S287

Krause, S., Rydall, A., Hales, S., Rodin, G., \& Lo, C. (2015). Initial validation of the Death and Dying Distress Scale for the assessment of death anxiety in patients with advanced cancer. Journal of Pain and Symptom Management, 49(1), 126-134. https://doi. org/10.1016/j.jpainsymman.2014.04.012126

Ladouceur, R., Blais, F., Freeston, M. H., \& Dugas, M. J. (1998). Problem solving and problem orientation in generalized anxiety disorder. Journal of Anxiety Disorders, 12(2), 139-152. https:// doi.org/10.1016/S0887-6185(98)00002-4

Lambert, C. E., Jr., \& Lambert, V. A. (1999). Psychological hardiness: State of the science. Holistic Nursing Practice, 13(3), 11-19. https://doi.org/10.1097/00004650-199904000-00004

Lambert, V. A., Lambert, C. E., \& Yamase, H. (2003). Psychological hardiness, workplace stress and related stress reduction strategies. Nursing \& Health Sciences, 5(2), 181-184. https://doi.org/ 10.1046/j.1442-2018.2003.00150.x

Le Marne, K. M., \& Harris, L. M. (2016). Death anxiety, perfectionism and disordered eating. Behaviour Change, 33(4), 193-211. https://doi.org/10.1017/bec.2016.11

Lester, D. (1967). Experimental and correlational studies of the fear of death. Psychological Bulletin, 67(1), 27-36. https://doi.org/ $10.1037 / \mathrm{h} 0024068$

Lester, D. (1990). The Collett-Lester fear of death scale: The original version and a revision. Death Studies, 14(5), 451-468. https:// doi.org/10.1080/07481189008252385

Locke, A., Kirst, N., \& Shultz, C. G. (2015). Diagnosis and management of generalized anxiety disorder and panic disorder in adults. American Family Physician, 91(9), 617-624.

Lyubomirsky, S., King, L., \& Diener, E. (2005). The benefits of frequent positive affect: Does happiness lead to success? Psychological Bulletin, 131(6), 803-855. https://doi.org/10.1037/00332909.131.6.803

Lyke, J. (2013). Associations Among Aspects of Meaning in Life and Death Anxiety in Young Adults. Death Studies, 37(5), 471-482. https://doi.org/10.1080/07481187.2011.649939

Maddi, S. R. (1997). Personal Views Survey II: A measure of dispositional hardiness. In C. P. Zalaquett \& R. J. Wood (Eds.),
Evaluating stress: A book of resources (pp. 293-309). Scarecrow Education.

Maddi, S. R. (1999). The personality construct of hardiness, I: Effect on experiencing, coping, and strain. Consulting Psychology Journal, 51, 83-94. https://doi.org/10.1037/1061-4087.51.2.83

Maddi, S. R. (2002). The story of hardiness: Twenty years of theorizing, research, and practice. Consulting Psychology Journal, 54, 173-185. https://doi.org/10.1037/1061-4087.54.3.173

Maddi, S. R. (2004). Hardiness: An operationalization of existential courage. Journal of Humanistic Psychology, 44(3), 279-298. https://doi.org/10.1177/0022167804266101

Maddi, S. R., \& Khoshaba, D. M. (2001). Personal Views Survey III-R: Internet instruction manual. Hardiness Institute Press.

Martela, F., \& Steger, M. F. (2016). The three meanings of meaning in life: Distinguishing coherence, purpose, and significance. The Journal of Positive Psychology, 11(5), 531-545. https://doi.org/ 10.1080/17439760.2015.1137623

Martens, E. J., de Jonge, P., Na, B., Cohen, B. E., Lett, H., \& Whooley, M. A. (2010). Scared to death? Generalized anxiety disorder and cardiovascular events in patients with stable coronary heart disease: The Heart and Soul Study. Archives of General Psychiatry, 67(7), 750-758. https://doi.org/10.1001/archgenpsychiatry.2010. 74

Maxfield, M., John, S., \& Pyszczynski, T. (2014). A terror management perspective on the role of death-related anxiety in psychological dysfunction. The Humanistic Psychologist, 42(1), 35-53. https:// doi.org/10.1080/08873267.2012.732155

Mendlowicz, M. V., \& Stein, M. B. (2000). Quality of life in individuals with anxiety disorders. American Journal of Psychiatry, 157(5), 669-682.

Menzies, R. E., \& Dar-Nimrod, I. (2017). Death anxiety and its relationship with obsessive-compulsive disorder. Journal of Abnormal Psychology, 126(4), 367-377. https://doi.org/10.1037/abn00 00263

Menzies, R. E., \& Menzies, R. G. (2020). Death anxiety in the time of COVID-19: Theoretical explanations and clinical implications. The Cognitive Behaviour Therapist, 13, 1-19. https://doi.org/10. 1017/S1754470X20000215

Menzies, R. E., Sharpe, L., \& Dar-Nimrod, I. (2019). The relationship between death anxiety and severity of mental illnesses. British Journal of Clinical Psychology, 58(4), 452-467. https://doi.org/ 10.1111/bjc.12229

Menzies, R. E., Zuccala, M., Sharpe, L., \& Dar-Nimrod, I. (2020). Are anxiety disorders a pathway to obsessive-compulsive disorder? Different trajectories of OCD and the role of death anxiety. Nordic journal of psychiatry, 1-6. https://doi.org/10.1080/08039488. 2020.1817554

Metts, A., Zinbarg, R., Hammen, C., Mineka, S., \& Craske, M. G. (2021). Extraversion and interpersonal support as risk, resource, and protective factors in the prediction of unipolar mood and anxiety disorders. Journal of Abnormal Psychology, 130(1), 47-59. https://doi.org/10.1037/abn0000643

Miller, A. K., Lee, B. L., \& Henderson, C. E. (2012). Death anxiety in persons with HIV/AIDS: A systematic review and meta-analysis. Death Studies, 36(7), 640-663. https://doi.org/10.1080/07481 187.2011.604467

Miloyan, B., \& Pachana, N. A. (2015). Clinical significance of worry and physical symptoms in late-life generalized anxiety disorder. International Journal of Geriatric Psychiatry, 30(12), 11861194. https://doi.org/10.1002/gps.4273

Miloyan, B., Byrne, G. J., \& Pachana, N. A. (2014). Age-related changes in generalized anxiety disorder symptoms. International Psychogeriatrics, 26(4), 565-572. https://doi.org/10.1017/S1041 610213002470 
Monroe, S. M., \& Simons, A. D. (1991). Diathesis-stress theories in the context of life stress research: Implications for the depressive disorders. Psychological Bulletin, 110(3), 406-425. https://doi.org/10.1037/0033-2909.110.3.406

Naghiyaee, M., Bahmani, B., \& Asgari, A. (2020). The psychometric properties of the meaning in life questionnaire (MLQ) in patients with life-threatening illnesses. The scientific world journal, 1-9. https://doi.org/10.1155/2020/8361602

Neimeyer, R. A., Wittkowski, J., \& Moser, R. P. (2004). Psychological research on death attitudes: An overview and evaluation. Death Studies, 28(4), 309-340. https://doi.org/10.1080/07481 180490432324

Nguyen, T. D., Shultz, C. J., \& Westbrook, M. D. (2012). Psychological hardiness in learning and quality of college life of business students: Evidence from Vietnam. Journal of Happiness Studies, 13(6), 1091-1103. https://doi.org/10.1007/s10902-011-9308-0

Nicholson, T., Higgins, W., Turner, P., James, S., Stickle, F., \& Pruitt, T. (1994). The relation between meaning in life and the occurrence of drug abuse: A retrospective study. Psychology of Addictive Behaviors, 8(1), 24-28.

Nolen-Hoeksema, S., Wisco, B. E., \& Lyubomirsky, S. (2008). Rethinking Rumination. Perspectives on Psychological Science, 3(5), 400-424. https://doi.org/10.1111/j.1745-6924.2008. 00088.x

Noyes, J. R., Stuart, S., Longley, S. L., Langbehn, D. R., \& Happel, R. L. (2002). Hypochondriasis and fear of death. The Journal of Nervous and Mental Disease, 190(8), 503-509.

O’Connor, B. P., \& Vallerand, R. J. (1998). Psychological adjustment variables as predictors of mortality among nursing home residents. Psychology and Aging, 13(3), 368-374. https://doi.org/ 10.1037/0882-7974.13.3.368

Ozanne, A. O., Graneheim, U. H., \& Strang, S. (2013). Finding meaning despite anxiety over life and death in amyotrophic lateral sclerosis patients. Journal of Clinical Nursing, 22(15-16), 21412149. https://doi.org/10.1111/jocn.12071

Öner, N., \& Le Compte, V. A. (1985). State-Trait Anxiety Inventory handbook. Boğaziçi University Publishing.

Öngider, N., \& Özışı Eyüboğlu, S. (2013). Investigation of death anxiety among depressive patients. Journal of Clinical Psychiatry, $16(1), 34-46$.

Ozcan, M., Uguz, F., \& Cilli, A. S. (2006). The prevalence of generalized anxiety disorder and comorbidity among psychiatric outpatients. Turkish Journal of Psychiatry, 17(4), 1-9.

Pandya, A. K., \& Kathuria, T. (2021). Death Anxiety, Religiosity and Culture: Implications for Therapeutic Process and Future Research. Religions, 12(1), 61. https://doi.org/10.3390/rel12 010061

Park, C. L. (2010). Making sense of the meaning literature: An integrative review of meaning making and its effects on adjustment to stressful life events. Psychological Bulletin, 136(2), 257-301. https://doi.org/10.1037/a0018301

Pedersen, H. F., Birkeland, M. H., Jensen, J. S., Schnell, T., Hvidt, N. C., Sørensen, T., \& La Cour, P. (2018). What brings meaning to life in a highly secular society? A study on sources of meaning among Danes. Scandinavian journal of psychology, 59(6), 678-690. https://doi.org/10.1111/sjop.12495.

Pourakbari, F., Khajevand Khoshli, A., \& Asadi, J. (2014). Relationship of psychological hardiness and quality of life with death anxiety in nurses. Journal of Research Development in Nursing \& Midwifery, 11(2), 53-59.

Pyszczynski, T., Greenberg, J., Solomon, S., Arndt, J., \& Schimel, J. (2004). Why Do People Need Self-Esteem? A Theoretical and Empirical Review. Psychological Bulletin, 130(3), 435-468. https://doi.org/10.1037/0033-2909.130.3.435

Rappaport, H., Fossler, R. J., Bross, L. S., \& Gilden, D. (1993). Future time, death anxiety, and life purpose among older adults. Death
Studies, 17(4), 369-379. https://doi.org/10.1080/0748118930 8252631

Rasmussen, C. A., \& Brems, C. (1996). The relationship of death anxiety with age and psychosocial maturity. The Journal of Psychology, 130(2), 141-144. https://doi.org/10.1080/00223980.1996. 9914996

Reker, G. T. (2005). Meaning in life of young, middle-aged, and older adults: Factorial validity, age, and gender invariance of the Personal Meaning Index (PMI). Personality and Individual Differences, 38(1), 71-85. https://doi.org/10.1016/j.paid.2004.03.010

Roemer, L., Lee, J. K., Salters-Pedneault, K., Erisman, S. M., Orsillo, S. M., \& Mennin, D. S. (2009). Mindfulness and emotion regulation difficulties in generalized anxiety disorder: Preliminary evidence for independent and overlapping contributions. Behavior Therapy, 40(2), 142-154. https://doi.org/10.1016/j.beth.2008. 04.001

Roemer, L., \& Orsillo, S. M. (2002). Expanding our conceptualization of and treatment for generalized anxiety disorder: Integrating mindfulness/acceptance-based approaches with existing cognitive-behavioral models. Clinical Psychology: Science and Practice, 9(1), 54-68. https://doi.org/10.1093/clipsy.9.1.54

Roemer, L., Orsillo, S. M., \& Salters-Pedneault, K. (2008). Efficacy of an acceptance-based behavior therapy for generalized anxiety disorder: Evaluation in a randomized controlled trial. Journal of Consulting and Clinical Psychology, 76(6), 1083-1089.

Roest, A. M., Zuidersma, M., \& de Jonge, P. (2012). Myocardial infarction and generalised anxiety disorder: 10-year follow-up. The British Journal of Psychiatry, 200(4), 324-329. https://doi.org/ 10.1192/bjp.bp.111.103549

Routledge, C., \& Juhl, J. (2010). When death thoughts lead to death fears: Mortality salience increases death anxiety for individuals who lack meaning in life. Cognition and Emotion, 24(5), 848-854. https://doi.org/10.1080/02699930902847144

Sandvik, A. M., Gjevestad, E., Aabrekk, E., et al. (2020). Physical Fitness and Psychological Hardiness as Predictors of Parasympathetic Control in Response to Stress: A Norwegian Police Simulator Training Study. Journal of Police and Criminal Psychology, 35, 504-517. https://doi.org/10.1007/s11896-019-09323-8

Sandvik, A. M., Hansen, A. L., Hystad, S. W., Johnsen, B. H., \& Bartone, P. T. (2015). Psychopathy, anxiety, and resiliency-Psychological hardiness as a mediator of the psychopathy-anxiety relationship in a prison setting. Personality and Individual Differences, 72, 30-34. https://doi.org/10.1016/j.paid.2014.08.009

Saxena, S. (2015). Relationship between psychological hardiness and mental health among college students. Indian Journal of Health \& Wellbeing, 6(8), 823-825.

Schnell, T. (2009). The Sources of Meaning and Meaning in Life Questionnaire (SoMe): Relations to demographics and well-being. The Journal of Positive Psychology, 4(6), 483-499. https://doi. org/10.1080/17439760903271074

Schulenberg, S. E., Strack, K. M., \& Buchanan, E. M. (2011). The Meaning in Life Questionnaire: Psychometric properties with individuals with serious mental illness in an inpatient setting. Journal of Clinical Psychology, 67, 1210-1219. https://doi.org/ 10.1002/jclp. 20841

Sezgin, F. (2009). Relationships between teacher organizational commitment, psychological hardiness and some demographic variables in Turkish primary schools. Journal of Educational Administration, 47(5), 630-651. https://doi.org/10.1108/09578 230910981099

Shakespeare-Finch, J., \& Lurie-Beck, J. (2014). A meta-analytic clarification of the relationship between posttraumatic growth and symptoms of posttraumatic distress disorder. Journal of Anxiety Disorders, 28(2), 223-229. https://doi.org/10.1016/j.janxd is.2013.10.005 
Shiah, Y. J., Chang, F., Chiang, S. K., Lin, I. M., \& Tam, W. C. C. (2015). Religion and health: Anxiety, religiosity, meaning of life and mental health. Journal of Religion and Health, 54(1), 35-45. https://doi.org/10.1007/s10943-013-9781-3

Singley, K. I., Hale, B. D., \& Russell, D. M. (2012). Heart rate, anxiety, and hardiness in novice (tandem) and experienced (solo) skydivers. Journal of Sport Behavior, 35(4), 453-469.

Smith, B. W., \& Zautra, A. J. (2004). The role of purpose in life in recovery from knee surgery. International Journal of Behavioral Medicine, 11(4), 197-202. https://doi.org/10.1207/s15327558i jbm1104_2

Spielberger, C. D. (1983). Manual for the State-Trait Anxiety Inventory: STAI (Form Y). Consulting Psychologists Press.

Starcevic, V. (2007). Body as the source of threat and fear of death is hypochondriasis and panic disorder. Psihijatrija Danas, 39, 73-82.

Stein, M. B., \& Sareen, J. (2015). Generalized anxiety disorder. New England Journal of Medicine, 373(21), 2059-2068. https://doi. org/10.1056/NEJMcp1502514

Stein, D., Zinman, D., Halevy, L., Yaroslavsky, A., Bachar, E., Kreitler, S., \& Orbach, I. (2013). Attitudes toward life and death and suicidality among inpatient female adolescents with eating disorders. The Journal of Nervous and Mental Disease, 201(12), 1066-1071.

Steger, M. F., Beeby, A., Garrett, S., \& Kashdan, T. B. (2013). Creating a stable architectural framework of existence: Proposing a model of lifelong meaning. In S. A. David, I. Boniwell, \& A. C. Ayers (Eds.), The Oxford handbook of happiness (pp. 101-118). Oxford University Press.

Steger, M. F., \& Frazier, P. (2005). Meaning in life: One link in the chain from religiousness to wellbeing. Journal of Counseling Psychology, 52(4), 574-582. https://doi.org/10.1037/0022-0167. 52.4.574

Steger, M. F., Frazier, P., Oishi, S., \& Kaler, M. (2006). The Meaning in Life Questionnaire: Assessing the presence of and search for meaning in life. Journal of Counseling Psychology, 53(1), 80-93. https://doi.org/10.1037/0022-0167.53.1.80

Steger, M. F., \& Kashdan, T. B. (2007). Stability and specificity of meaning in life and life satisfaction over one year. Journal of Happiness Studies, 8(2), 161-179. https://doi.org/10.1007/ s10902-006-9011-8

Steger, M. F., Kashdan, T. B., Sullivan, B. A., \& Lorentz, D. (2008a). Understanding the search for meaning in life: Personality, cognitive style, and the dynamic between seeking and experiencing meaning. Journal of Personality, 76, 199-228. https://doi.org/ 10.1111/j.1467-6494.2007.00484.x

Steger, M. F., Kawabata, Y., Shimai, S., \& Otake, K. (2008b). The meaningful life in Japan and the United States: Levels and correlates of meaning in life. Journal of Research in Personality, 42(3), 660-678. https://doi.org/10.1016/j.jrp.2007.09.003

Steger, M. F., Mann, J. R., Michels, P., \& Cooper, T. C. (2009a). Meaning in life, anxiety, depression, and general health among smoking cessation patients. Journal of Psychosomatic Research, 67(4), 353-358. https://doi.org/10.1016/j.jpsychores.2009.02.006

Steger, M. F., Oishi, S., \& Kashdan, T. B. (2009b). Meaning in life across the life span: Levels and correlates of meaning in life from emerging adulthood to older adulthood. The Journal of Positive Psychology, 4(1), 43-52. https://doi.org/10.1080/17439 760802303127

Steger, M. F., \& Park, C. L. (2012). The creation of meaning following trauma: Meaning making and trajectories of distress and recovery. In T. Keane, E. Newman, \& K. Fogler (Eds.), Toward an integrated approach to trauma focused therapy: Placing evidence-based interventions in an expanded psychological context (pp. 171-191). APA Press.
Stolorow, R. D. (1979). Defensive and arrested developmental aspects of death anxiety, hypochondriasis and depersonalization. International Journal of Psycho-Analysis, 60, 201-213.

Stöber, J., Tepperwien, S., \& Staak, M. (2000). Worrying leads to reduced concreteness of problem elaborations: Evidence for the avoidance theory of worry. Anxiety, Stress \& Coping, 13(3), 217-227. https://doi.org/10.1080/10615800008549263

Strachan, E., Schimel, J., Arndt, J., Williams, T., Solomon, S., Pyszczynski, T., \& Greenberg, J. (2007). Terror mismanagement: Evidence that mortality salience exacerbates phobic and compulsive behaviors. Personality and Social Psychology Bulletin, 33(8), 1137-1151. https://doi.org/10.1177/0146167207303018

Suhail, K., \& Akram, S. (2002). Correlates of death anxiety in Pakistan. Death Studies, 26(1), 39-50. https://doi.org/10.1080/ 07481180210146

Şenol, C. (1989). Ankara ilinde kurumlarda yaşayan yaşlılarda ölüme ilişkin kaygl ve korkular [Anxieties and fears about death in the elderly living in institutions in Ankara] (Unpublished Master's thesis). Ankara University.

Tabachnick, B. G., \& Fidell, L. S. (2007). Using multivariate statistics (5th ed.). Allyn \& Bacon.

Tang, C. S. K., Wu, A. M., Yan, W., \& E. C. (2002). Psychosocial correlates of death anxiety among Chinese college students. Death Studies, 26(6), 491-499. https://doi.org/10.1080/0748118027 60139012

Tanhan, A. (2019). Acceptance and commitment therapy with ecological systems theory: Addressing Muslim mental health issues and wellbeing. Journal of positive psychology \& wellbeing, 3(2), 197-219. https://doi.org/10.47602/jpsp.v3i2.172

Tanhan, A., \& Strack, R. W. (2020). Online photovoice to explore and advocate for Muslim biopsychosocial spiritual wellbeing and issues: Ecological systems theory and ally development. Current Psychology, 39, 2010-2025. https://doi.org/10.1007/ s12144-020-00692-6

Tedeschi, R. G., \& Calhoun, L. G. (2004). Posttraumatic growth: Conceptual foundations and empirical evidence. Psychological Inquiry, 15(1), 1-18. https://doi.org/10.1207/s15327965pli1501_ 01

Tegin, B. (1980). Depresyonde bilişsel bozukluklar: Beck modeline göre bir inceleme. [Cognitive Disorders in Depression: An investigation based on Beck's model] (Unpublished dissertation). Ankara, Turkey: Hacettepe University Social Sciences Institute.

Templer, D. I. (1970). The construction and validation of a death anxiety scale. Journal of General Psychology, 82, 165-177.

Templer, D. I. (1976). Two factor theory of death anxiety: A note. Essence: Issues in the Study of Ageing Dying, and Death, 1(2), 91-93.

Templer, D. I., Awadalla, A., Al-Fayez, G., Frazee, J., Bassman, L., Connelly, H. J., ... \& Abdel-Khalek, A. M. (2006). Construction of a death anxiety scale-extended. OMEGA-Journal of death and dying, 53(3), 209-226. https://doi.org/10.2190/ BQFP-9ULN-NULY-4JDR

Tillich, P. (1952). The Courage to Be. Yale University Press.

Thorson, J. A., \& Powell, F. C. (1988). Elements of death anxiety and meanings of death. Journal of Clinical Psychology, 44(5), 691701. https://doi.org/10.1002/1097-4679(198809)44:5\%3c691:: AID-JCLP2270440505\%3e3.0.CO;2-D

Uddin, M. N., Bhar, S., \& Islam, F. M. A. (2019). An assessment of awareness of mental health conditions and its association with socio-demographic characteristics: A cross-sectional study in a rural district in Bangladesh. BMC Health Services Research, 19(1), 1-11. https://doi.org/10.1186/s12913-019-4385-6

Vehling, S., Lehmann, C., Oechsle, K., Bokemeyer, C., Krüll, A., Koch, U., \& Mehnert, A. (2011). Global meaning and meaningrelated life attitudes: Exploring their role in predicting depression, anxiety, and demoralization in cancer patients. Supportive 
Care in Cancer, 19(4), 513-520. https://doi.org/10.1007/ s00520-010-0845-6

Volkert, J., Härter, M., Dehoust, M. C., Ausín, B., Canuto, A., Da Ronch, C., ... \& Andreas, S. (2019). The role of meaning in life in community-dwelling older adults with depression and relationship to other risk factors. Aging \& mental health, 23(1), 100-106. https://doi.org/10.1080/13607863.2017.1396576

Wells, A. (1995). Meta-cognition and worry: A cognitive model of generalized anxiety disorder. Behavioural and Cognitive Psychotherapy, 23(3), 301-320. https://doi.org/10.1017/S135246580 0015897

Wells, A. (1999). A metacognitive model and therapy for generalized anxiety disorder. Clinical Psychology \& Psychotherapy: An International Journal of Theory \& Practice, 6(2), 86-95. https://doi.org/10.1002/(SICI)1099-0879(199905)6:2\%3c86:: AID-CPP189\%3e3.0.CO;2-S

Wells, A. (2005). The metacognitive model of GAD: Assessment of meta-worry and relationship with DSM-IV generalized anxiety disorder. Cognitive Therapy and Research, 29(1), 107-121. https://doi.org/10.1007/s10608-005-1652-0

Wittchen, H. U. (2002). Generalized anxiety disorder: Prevalence, burden, and cost to society. Depression and Anxiety, 16(4), 162-171. https://doi.org/10.1002/da.10065

Wittchen, H. U., \& Hoyer, J. (2001). Generalized anxiety disorder: Nature and course. The Journal of Clinical Psychiatry, 62(11), $15-19$.

Wong, P. T. P. (2000). Meaning of life and meaning of death in successful aging. In A. Tomer (Ed.), Death Attitudes and the Older Adult: Theories, Concepts, and Applications (pp. 23-35). Routledge Press.

Wong, P. T. P. (2008). Meaning management theory and death acceptance. In A. Tomer, E. Grafton, \& P. T. P. Wong (Eds.), Existential and spiritual issues in death attitudes (pp. 65-87). Erlbaum Press.

Wong, P. T. (2017). A decade of meaning: Past, present, and future. Journal of Constructivist Psychology, 30(1), 82-89. https://doi. org/10.1080/10720537.2015.1119085

Wong, P. T. P., \& Tomer, A. (2011). Beyond Terror and Denial: The Positive Psychology of Death Acceptance. Death Studies, 35(2), 99-106. https://doi.org/10.1080/07481187.2011.535377

Yalom, I. D. (2008). Staring at the sun: Overcoming the terror of death. Jossey-Bass Press.

Yek, M. H., Olendzki, N., Kekecs, Z., Patterson, V., \& Elkins, G. (2017). Presence of meaning in life and search for meaning in life and relationship to health anxiety. Psychological Reports, 120(3), 383-390. https://doi.org/10.1177/0033294117697084

Yüksel, M. Y., Güneş, F., \& Akdağ, C. (2017). Investigation of the death anxiety and meaning in life levels among middle-aged adults. Spiritual Psychology and Counseling, 2(2), 165-181.

Zhang, J., Peng, J., Gao, P., Huang, H., Cao, Y., Zheng, L., \& Miao, D. (2019). Relationship between meaning in life and death anxiety in the elderly: Self-esteem as a mediator. BMC Geriatrics, 19(1), 1-8. https://doi.org/10.1186/s12877-019-1316-7

Zuccala, M., \& Abbott, M. J. (2021). Social Anxiety Disorder and the Fear of Death: An Empirical Investigation of the Terror Management Approach towards Understanding Clinical Anxiety. Cognitive therapy and research, 1-14. https://doi.org/10. 1007/s10608-020-10187-0

Publisher's Note Springer Nature remains neutral with regard to jurisdictional claims in published maps and institutional affiliations. 